Hope College

Hope College Digital Commons

Faculty Publications

2-14-2019

\title{
Substrate-Dependent Photoconductivity Dynamics in a High- Efficiency Hybrid Perovskite Alloy
}

\author{
Ali Moeed Tirmzi \\ Cornell University \\ Jeffrey A. Christians \\ National Renewable Energy Laboratory; Hope College, christians@hope.edu \\ Ryan P. Dwyer \\ Cornell University \\ David T. Moore \\ National Renewable Energy Laboratory \\ John A. Marohn \\ Cornell University \\ Follow this and additional works at: https://digitalcommons.hope.edu/faculty_publications \\ Part of the Engineering Commons, and the Physical Chemistry Commons
}

\section{Recommended Citation}

Repository citation: Tirmzi, Ali Moeed; Christians, Jeffrey A.; Dwyer, Ryan P.; Moore, David T.; and Marohn, John A., "Substrate-Dependent Photoconductivity Dynamics in a High-Efficiency Hybrid Perovskite Alloy" (2019). Faculty Publications. Paper 1515.

https://digitalcommons.hope.edu/faculty_publications/1515

Published in: The Journal of Physical Chemistry C, Volume 123, Issue 6, February 14, 2019, pages 3402-3415. Copyright @ 2019 American Chemical Society.

This Article is brought to you for free and open access by Hope College Digital Commons. It has been accepted for inclusion in Faculty Publications by an authorized administrator of Hope College Digital Commons. For more information, please contact digitalcommons@hope.edu. 


\title{
Substrate-Dependent Photoconductivity Dynamics in a High- Efficiency Hybrid Perovskite Alloy
}

\author{
Ali Moeed Tirmzi, ${ }^{\dagger}$ Jeffrey A. Christians, ${ }^{\ddagger}$ Ryan P. Dwyer, ${ }^{\dagger}{ }^{\circ}$ David T. Moore, \\ and John A. Marohn*, ${ }^{*}$ \\ ${ }^{\dagger}$ Department of Chemistry and Chemical Biology, Cornell University, Ithaca, New York 14853, United States \\ ${ }^{\ddagger}$ National Renewable Energy Laboratory, Golden, Colorado 80401, United States
}

\section{Supporting Information}

\begin{abstract}
Films of $\left(\mathrm{FA}_{0.79} \mathrm{MA}_{0.16} \mathrm{Cs}_{0.05}\right)_{0.97} \mathrm{~Pb}\left(\mathrm{I}_{0.84} \mathrm{Br}_{0.16}\right)_{2.97}$ were grown over $\mathrm{TiO}_{2}, \mathrm{SnO}_{2}$, indium tin oxide (ITO), and $\mathrm{NiO}$. Film conductivity was interrogated by measuring the in-phase and out-of-phase forces acting between the film and a charged microcantilever. We followed the films' conductivity versus time, frequency, light intensity, and temperature (233$312 \mathrm{~K}$ ). Perovskite conductivity was high and light-independent over ITO and $\mathrm{NiO}$. Over $\mathrm{TiO}_{2}$ and $\mathrm{SnO}_{2}$, the conductivity was low in the dark, increased with light intensity, and persisted for 10's of seconds after the light was removed. At an elevated temperature over $\mathrm{TiO}_{2}$, the rate of conductivity recovery in the dark showed an activated temperature dependence $\left(E_{\mathrm{a}}=0.58\right.$ eV). Surprisingly, the light-induced conductivity over $\mathrm{TiO}_{2}$ and $\mathrm{SnO}_{2}$ relaxed essentially instantaneously at a low temperature. We use a transmission-line model for mixed ionic-electronic conductors to show that the measurements presented are sensitive to the sum of electronic and ionic conductivities. We rationalize the seemingly incongruous observations using the idea that holes, introduced either by equilibration with the substrate or via optical irradiation, create iodide vacancies.

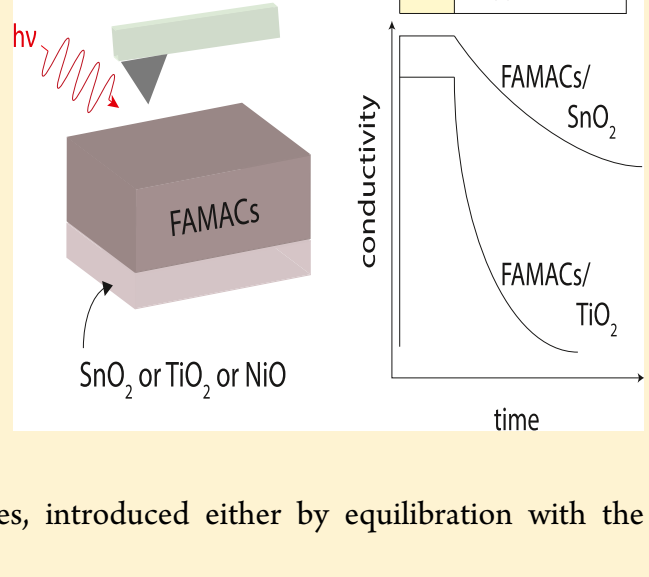

\section{INTRODUCTION}

The extraordinary performance of solar cells made from solution-processed lead-halide perovskite semiconductors is attributed to the material's remarkably high defect tolerance and low exciton binding energy. ${ }^{1-5}$ The theoretically predicted ionic defect formation energy is relatively low, and consequently the equilibrium defect concentration should be quite high., ${ }^{2,6}$ For perovskite solar cells to reach their Shockley-Queisser limit, it is necessary to understand how these defects form and identify which ones contribute to nonradiative recombination, loss of photovoltage, and device hysteresis. ${ }^{7,8}$

At equilibrium, the concentration of a specific defect in a leadhalide perovskite crystal depends on the concentration (i.e., the chemical potential) of the relevant chemical species present in the solution or vapor from which the perovskite was precipitated. $^{1-3,5,9}$ Non-equilibrium growth of the perovskite in the thin-film form ${ }^{10}$ should generate additional point- and grain-boundary defects. The concentration of defects in the crystal also depends on the electron and hole chemical potential which-if the perovskite's background carrier concentration is sufficiently low-could be strongly affected by the substrate. Evidence that the substrate affects band alignment and induces p- or n-type conductivity can be seen in X-ray photoelectron spectroscopy, ${ }^{11}$ ultraviolet photoelectron spectroscopy, ${ }^{12,13}$ and inverse photoemission spectroscopy ${ }^{12}$ measurements of leadhalide perovskite films, in one example in a film as thick as 400 $\mathrm{nm} .{ }^{12}$ How the substrate changes the near-surface and bulk conductivity of the perovskite is a topic of current research; ${ }^{13}$ effects include the formation of an interface dipole, the creation of a chemically distinct passivation layer, and substrate-induced changes in perovskite film morphology.

Defects in halide perovskites are challenging to study for a number of reasons. Many of these defects are mobile under the application of electric field and/or light, with iodine species and vacancies considered to be most mobile species. ${ }^{14-22}$ Moreover, recent reports by Maier and co-workers show that the concentration of mobile iodine vacancies depends on illumination intensity. ${ }^{19}$ This effect, which is expected from defectenergy calculations, ${ }^{1,3,9}$ needs to be considered in addition to the established effects of light on charge motion and polarization when trying to understand light-related hysteresis phenomena. ${ }^{15,20,23-29}$

Here, we study a high-performing material with precursor solution stoichiometry $\left(\mathrm{FA}_{0.79} \mathrm{MA}_{0.16} \mathrm{Cs}_{0.05}\right)_{0.97} \mathrm{~Pb}\left(\mathrm{I}_{0.84} \mathrm{Br}_{0.16}\right)_{2.97}$ (hereafter referred to as FAMACs) grown over four different substrates $-\mathrm{TiO}_{2}, \mathrm{SnO}_{2}$, indium tin oxide (ITO), and $\mathrm{NiO} .^{30-32}$ Christians and co-workers reported $1000 \mathrm{~h}$ operational stability for FAMACs devices prepared with an $\mathrm{SnO}_{2}$ electron acceptor layer. ${ }^{30}$ When compared to $\mathrm{TiO}_{2}$-based devices, the $\mathrm{SnO}_{2}$ devices were much more stable. While

Received: December 6, 2018

Revised: January 17, 2019

Published: January 17, 2019 
degradation of $\mathrm{TiO}_{2}$ devices has previously solely been attributed to ultraviolet light-induced degradation, ${ }^{33,34}$ they revealed, using time-of-flight secondary ion mass spectrometry (ToF-SIMS) measurements, different ionic distributions in $\mathrm{TiO}_{2}$ - and $\mathrm{SnO}_{2}$-based devices after several hours of operation. This observation demonstrates a clear difference in the light and/or electric field induced ion/vacancy motion in $\mathrm{SnO}_{2}$ - and $\mathrm{TiO}_{2}$-based devices.

Motivated by these findings, here we measure the ac conductivity of the FAMACs films in the $\mathrm{kHz}$ to $\mathrm{MHz}$ regime and study this conductivity as a function of light intensity, time, and temperature. We show that the light-on conductivity returns to its initial light-off value on two distinct timescales (sub $100 \mathrm{~ms}$ and 10's of seconds) in the material grown on the electron accepting substrates $\mathrm{TiO}_{2}$ and $\mathrm{SnO}_{2}$. In contrast, material grown on the hole acceptor ( $\mathrm{NiO}$ ) and ITO substrates shows frequency-independent conductivity. We tentatively assign these distinct behaviors to differences in the perovskites' background carrier type and concentration. We find that the $\mathrm{SnO}_{2}$-substrate films show higher dark conductivity and slower relaxation than the $\mathrm{TiO}_{2}$-substrate films. We show that at room temperature and above, the relaxation of the conductivity is activated over $\mathrm{TiO}_{2}$ (and possibly over $\mathrm{SnO}_{2}$ also). Surprisingly, the relaxation of conductivity becomes considerably faster when the sample is cooled to a low temperature of $233 \mathrm{~K}$. The simplest explanation we can devise for these diverse observations is that the measured conductivity changes arise from light-dependent electronic fluctuations; at room temperature, these electronic fluctuations are coupled to slow, light-induced ionic/vacancy fluctuations that are frozen out at a low temperature. Our observation that the timescale of the conductivity recovery in the $\mathrm{SnO}_{2}$-substrate sample is much slower than in the $\mathrm{TiO}_{2}$ substrate sample supports the Christians et al. hypothesis of slower ionic motion in the $\mathrm{SnO}_{2}$-substrate sample compared to the $\mathrm{TiO}_{2}$-substrate sample. ${ }^{30}$

These experiments were motivated by our previously reported scanning probe microscopy (SPM) study of light- and timedependent conductivity in a thin film of $\mathrm{CsPbBr}_{3}{ }^{35}$ We used sample-induced dissipation ${ }^{36-49}$ and broadband local dielectric spectroscopy (BLDS) ${ }^{50}$ to demonstrate for $\mathrm{CsPbBr}_{3}$ that conductivity shows a slow activated recovery when the light was switched off, with an activation energy and time-scale consistent with ion motion. We concluded that the sample conductivity dynamics were controlled by the coupled motion of slow and fast charges. While $\mathrm{CsPbBr}$ served as a sample robust to temperature- and light-induced degradation, it has a relatively high band gap and is thus poorly suited for use in high-efficiency solar cells. Many high-efficiency devices reported to date rely on a mixed cation/anion perovskite absorber layer (such as FAMACs) to reach the desired band gap and enhanced stability needed for photovoltaic applications. The goal of the present study is to ascertain whether the conductivity dynamics observed for $\mathrm{CsPbr}_{3}$ are evident in FAMACs films and to see whether they are substrate-dependent.

As in ref 35 , here we follow conductivity dynamics using a charged microcantilever. Microcantilevers are primarily used in scanning-probe microscope experiments to create images. However, they have also proven useful in nonscanning experiments because of their tremendous sensitivity as force sensors. Prior SPM studies of lead-halide perovskite solar-cell materials have used Kelvin probe force microscopy to observe the dependence of the surface potential and surface photovoltage on time, electric field, and light intensity in order to draw conclusions about the spatial distribution of charges and ions. ${ }^{51-62}$ In studies of organic solar cell materials, frequencyshift measurements have been used to follow the time evolution of photo-induced capacitance and correlate the photocapacitance risetime with device performance. ${ }^{63-67}$ Sample-induced dissipation has been used to monitor local dopant concentration in silicon ${ }^{44}$ and $\mathrm{GaAs}^{36}$ probing quantizied energy levels in quantum dots; ${ }^{38}$ examine photo-induced damage in organic solar cell materials; ${ }^{41,42}$ quantify local dielectric fluctuations in insulating polymers; ${ }^{43,46-49,68}$ and probe dielectric fluctuations and intracarrier interactions in semiconducting small molecules. ${ }^{39}$ Here, we make use of the tremendous sensitivity of a charged microcantilever to passively observe the time evolution of a thin-film sample's conductivity ${ }^{35}$ through changes in cantilever dissipation induced by conductivity-related electricfield fluctuations in the sample. ${ }^{69}$

\section{EXPERIMENTAL SECTION}

2.1. Materials. Methylammonium bromide $\left(\mathrm{CH}_{3} \mathrm{NH}_{3} \mathrm{Br}\right.$, $\mathrm{MABr}$ ) and formamidinium iodide $\left(\mathrm{CH}\left(\mathrm{NH}_{2}\right)_{2}, \mathrm{FAI}\right)$ were purchased from Dyesol and used as received. Lead(II) iodide (99.9985\% metals basis) and the $\mathrm{SnO}_{2}$ colloid precursor (tin(IV) oxide, $15 \%$ in $\mathrm{H}_{2} \mathrm{O}$ colloidal dispersion) were purchased from Alfa Aesar. All other chemicals were purchased from Sigma-Aldrich and used as received.

2.2. Oxide Layer Deposition. ITO glass was cleaned by sonication in acetone and isopropanol, followed by UV-ozone cleaning for $15 \mathrm{~min}$. Following cleaning, an additional thin oxide layer was deposited on the ITO glass (if necessary). $\mathrm{TiO}_{2}$ layers were deposited using a previously reported low temperature $\mathrm{TiO}_{2}$ process. Briefly, $\mathrm{TiO}_{2}$ nanoparticles were synthesized as reported previously by Wojciechowski et al. ${ }^{70}$ and a $1.18 \mathrm{wt} \%$ ethanolic suspension, along with $20 \mathrm{~mol} \%$ titanium diisopropoxide bis(acetylacetonate), was spin-cast onto the ITO substrates with the following procedure: $700 \mathrm{rpm}, 10 \mathrm{~s}$; $1000 \mathrm{rpm}, 10 \mathrm{~s} ; 2000 \mathrm{rpm}, 30 \mathrm{~s}$. Tin oxide electron transport layers (ETLs) were deposited on cleaned ITO substrates. ${ }^{71}$ The aqueous $\mathrm{SnO}_{2}$ colloid solution, obtained from Alfa Aesar, was diluted in water with a ratio of 1:6.5 and spin-cast at $3000 \mathrm{rpm}$ for $30 \mathrm{~s}$. Both the $\mathrm{TiO}_{2}$ and $\mathrm{SnO}_{2}$ films were then dried at $150^{\circ} \mathrm{C}$ for $30 \mathrm{~min}$ and cleaned for $15 \mathrm{~min}$ by UV-ozone immediately before use. $\mathrm{NiO}$ films were deposited from a solution of nickel nitrate hexahydrate and ethylenediamine in ethylene glycol following a previously reported procedure. ${ }^{72}$

2.3. FAMACs Perovskite Film Deposition. Deposition of the FAMACs perovskite layers was carried out in a nitrogen glovebox following the method reported in ref 31 . The precursor solution was made by dissolving $172 \mathrm{mg}$ FAI, $507 \mathrm{mg} \mathrm{PbI}_{2}, 22.4$ mg MABr, and $73.4 \mathrm{mg} \mathrm{PbBr}_{2}$ (1:1.1:0.2:0.2 mole ratio) and 40 $\mu \mathrm{L}$ of CsI stock solution [1.5 $\mathrm{M}$ in dimethyl sulfoxide (DMSO)] in $627 \mathrm{mg}$ dimethylformamide and $183 \mathrm{mg}$ DMSO $(4: 1 \mathrm{v} / \mathrm{v})$. The films were deposited by spin-coating this precursor solution with the following procedure: $1000 \mathrm{rpm}$ for $10 \mathrm{~s}, 6000 \mathrm{rpm}$ for $20 \mathrm{~s}$. While the substrate was spinning, $0.1 \mathrm{~mL}$ of chlorobenzene was rapidly dripped onto the film with approximately $6 \mathrm{~s}$ remaining in the spin-coating procedure, forming a transparent orange film. The films were then annealed for $1 \mathrm{~h}$ at $100{ }^{\circ} \mathrm{C}$ to form highly specular FAMACs perovskite films.

2.4. Scanning Probe Microscopy. All experiments were performed under vacuum $\left(5 \times 10^{-6} \mathrm{mbar}\right)$ in a custom-built scanning Kelvin probe microscope described in detail elsewhere. ${ }^{6,73}$ The cantilever used was a MikroMasch HQ:NSC18/ Pt conductive probe. The resonance frequency and quality 
(a)

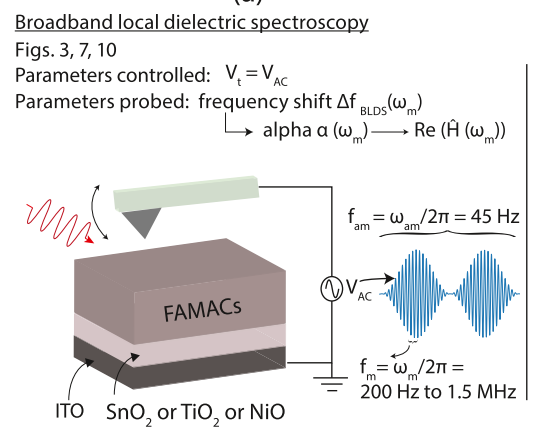

(b)

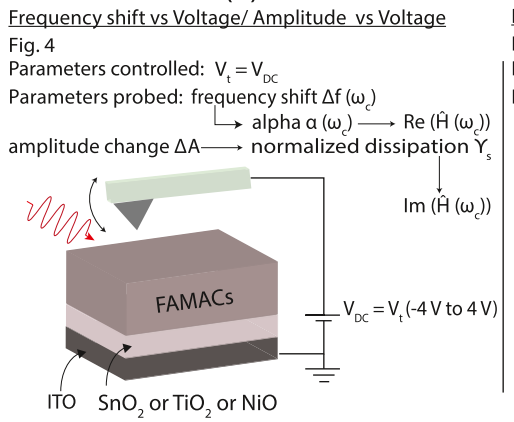

(c)

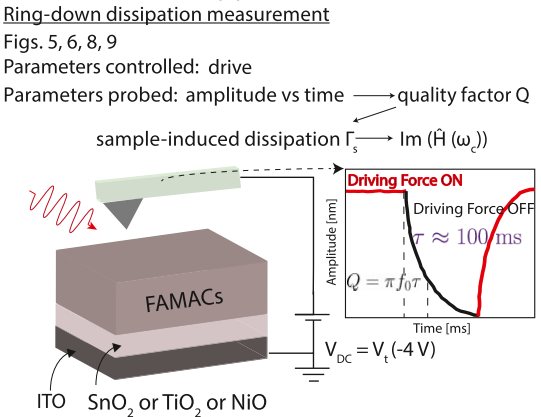

Figure 1. Schematic of the three scanning probe measurements used in this manuscript, highlighting the parameters that are controlled and probed. The measurements probe the complex frequency-dependent tip-sample transfer function $\hat{H}$ (eq 2 and Figure S2). (a) In a BLDS measurement, the tip voltage $V_{\mathrm{t}}=V_{\mathrm{ac}}\left(\omega_{\mathrm{m}}, \omega_{\mathrm{am}}\right)$ is amplitude-modulated at a fixed frequency of $f_{\mathrm{am}}=\omega_{\mathrm{am}} /(2 \pi)=45 \mathrm{~Hz}$ and sinusoidally modulated at a frequency $f_{\mathrm{m}}=\omega_{\mathrm{m}} /$ $(2 \pi)$ that is varied from $200 \mathrm{~Hz}$ to $1.5 \mathrm{MHz}$. At each $f_{\mathrm{m}}$, the component of the cantilever frequency shift $\Delta f_{\mathrm{BLDS}}\left(\omega_{\mathrm{m}}\right)$ at frequency $f_{\text {am }}$ is measured using a frequency demodulator and lock-in amplifier and $\alpha\left(\omega_{\mathrm{m}}\right)$ is calculated using eq 8 . The quantity $\alpha\left(\omega_{\mathrm{m}}\right)$ primarily measures $\operatorname{Re}\left(\hat{H}\left(\omega_{\mathrm{m}}\right)\right)($ eq 7$)$. (b) In a frequency shift $\Delta f$ vs $V_{\mathrm{t}}$ measurement or an amplitude $A$ vs $V_{\mathrm{t}}$ measurement, the tip voltage $V_{\mathrm{t}}=V_{\mathrm{dc}}$ is slowly varied from -4 to $+4 \mathrm{~V}$, while the cantilever frequency shift $\Delta f$ and the cantilever amplitude $A$ are recorded. From $\Delta f$, a voltage-normalized frequency shift $\alpha\left(\omega_{0}\right)$ is calculated using eq S4; the quantity $\alpha\left(\omega_{0}\right)$ primarily measures $\operatorname{Re}\left(\hat{H}\left(\omega_{c}\right)\right)$. From $A$, a voltage-normalized sample-induced dissipation $\gamma_{\mathrm{s}}$ is calculated using eq S9; the quantity $\gamma_{\mathrm{s}}$ primarily measures $\operatorname{Im}\left(\hat{H}\left(\omega_{\mathrm{c}}\right)\right)$ (eqs 6 and S8). (c) In a ring-down dissipation measurement, the cantilever drive is periodically switched off, the cantilever amplitude is measured as a function of time, and the cantilever's mechanical quality factor $Q$ is calculated from this ring-down transient. The observed change in $Q$ is converted to an equivalent change in sample-induced dissipation $\Gamma_{\mathrm{s}}$ using eq $S 10$. The parameter $\Gamma_{s}$ primarily measures $\operatorname{Im}\left(\hat{H}\left(\omega_{\mathrm{c}}\right)\right)($ eq 6$)$.

factor were obtained from ringdown measurements and found to be $\omega_{\mathrm{c}} / 2 \pi=f_{\mathrm{c}}=70.350 \mathrm{kHz}$ and $Q=24000$, respectively, at room temperature. The manufacturer's specified resonance frequency and spring constant were $f_{\mathrm{c}}=60$ to $75 \mathrm{kHz}$ and $k=3.5$ $\mathrm{N} \mathrm{m}{ }^{-1}$. Cantilever motion was detected using a fiber interferometer operating at $1490 \mathrm{~nm}$ (Corning model SMF-28 fiber). More experimental details regarding the implementation of BLDS and other measurements can be found in the Supporting Information.

\section{RESULTS}

3.1. Theoretical Background. Let us begin by summarizing the equations we will use to connect scanning-probe data to sample properties. Interested readers are directed to refs ${ }^{35,69}$ for a detailed derivation of the following equations. In our measurements, we modulate the charge on the cantilever tip and the sample and observe the resulting change in the cantilever frequency or amplitude. This charge is modulated by physically oscillating the cantilever, by applying a time-dependent voltage to the cantilever tip, or by doing both simultaneously. A summary of the distinct measurements carried out below is given in Figure 1.

Changes in the cantilever frequency and amplitude may be expressed in terms of a transfer function $H$ which relates the voltage $V_{\mathrm{ts}}$ applied to the cantilever tip (the sample substrate is grounded) to the voltage $V_{\mathrm{t}}$ dropped between the cantilever tip and the sample surface. The cantilever is modeled electrically as a capacitor $C_{\text {tip }}$, while the sample is modeled as resistor $R_{\mathrm{s}}$ operating in parallel with a capacitor $C_{s}$ (Figure S2). The resulting transfer function is given in the frequency domain by

$$
\hat{H}(\omega)=\frac{\hat{V}_{\mathrm{t}}(\omega)}{\hat{V}_{\mathrm{ts}}(\omega)}=\frac{\left(\mathrm{j} \omega C_{\mathrm{tip}}\right)^{-1}}{\left(R_{\mathrm{s}}^{-1}+\mathrm{j} \omega C_{\mathrm{s}}\right)^{-1}+\left(\mathrm{j} \omega C_{\mathrm{tip}}\right)^{-1}}
$$

which simplifies to

$$
\hat{H}(\omega)=\frac{1+j g^{-1} \omega \tau_{\text {fast }}}{1+j \omega \tau_{\text {fast }}}
$$

where $\left(R_{\mathrm{s}}^{-1}+\mathrm{j} \omega C_{\mathrm{s}}\right)^{-1}$ defines the sample impedance $Z$. The transfer function $H$ can be viewed as a lag compensator whose time constant and gain parameter are given by, respectively,

$$
\tau_{\text {fast }}=R_{\mathrm{s}}\left(C_{\mathrm{s}}+C_{\text {tip }}\right)=R_{\mathrm{s}} C_{\text {tot }} \text { and } g=C_{\text {tot }} / C_{\mathrm{s}}
$$

We give the time constant the subscript "fast" because of the time constant's similarity to " $\tau_{\text {fast }}$ " measured in impedance spectroscopy. ${ }^{35}$ We show experimentally below that $C_{\text {tip }} \gg C_{s}$; consequently, $\tau_{\text {fast }} \approx R_{\mathrm{s}} C_{\text {tip }}$. This simplification allows us to associate photo-induced changes in cantilever frequency and amplitude to photo-induced changes in sample resistance or, equivalently, sample conductivity.

The complex-valued transfer function in eq 2 has a real part which determines the in-phase forces and an imaginary part which determines the out-of-phase forces acting on the cantilever. We show the equivalent circuit and plot the shape of transfer function in Figure S2. The frequency shift measurements presented in Figure $4 \mathrm{~b}$ probe the real part of the transfer function

$$
\begin{aligned}
\Delta f & =-\frac{f_{\mathrm{c}}}{2 k} \frac{\delta F^{\prime}}{A} \\
& =-\frac{f_{\mathrm{c}}}{4 k}\left(C_{\mathrm{q}}^{\prime \prime}+\Delta C^{\prime \prime} \operatorname{Re}\left(\hat{H}\left(\omega_{\mathrm{c}}\right)\right)\right)(V-\phi)^{2}
\end{aligned}
$$

where $f_{\mathrm{c}}=\omega_{\mathrm{c}} / 2 \pi$ is the resonance frequency, $k$ is the spring constant, and $A$ is the amplitude, respectively, of the cantilever; $F^{\prime}$ is the in-phase force; $C_{t}$ is the cantilever capacitance computed at rest with the cantilever at its equilibrium position; $\Delta C^{\prime \prime} \equiv 2\left(C_{\mathrm{t}}^{\prime}\right)^{2} / C_{\mathrm{t}}$, with primes indicating derivatives with respect to the tip-sample distance; $\Delta C_{\mathrm{q}}^{\prime \prime} \equiv C_{\mathrm{t}}^{\prime \prime}-\Delta C^{\prime \prime} ; V$ is the voltage applied to the cantilever tip; and $\phi$ is the surface potential. The variable $\alpha_{0}$ plotted in Figure $4 \mathrm{~b}$ is a voltagenormalized frequency shift, the curvature of the $\Delta f$ versus $V$ data defined by the equation $\Delta f=\alpha_{0}(V-\phi)^{2}$ and given by

$$
\alpha_{0}=-\frac{f_{\mathrm{c}}}{4 k}\left(C_{\mathrm{q}}^{\prime \prime}+\Delta C^{\prime \prime} \operatorname{Re}\left(\hat{H}\left(\omega_{\mathrm{c}}\right)\right)\right)
$$


From eq 5 , we can see that $\alpha_{0}$ is sensitive to the real part of the transfer function at frequency $\omega_{\mathrm{c}}$, with additional contributions from in-phase forces present at low frequency $(\omega / 2 \pi<0.1 \mathrm{~Hz})$. The sample-induced dissipation plotted in Figures $4 a, 5,6,8$, and 9 is sensitive to the out-of-phase part of the transfer function

$$
\Gamma_{\mathrm{s}}=-\frac{1}{\omega_{\mathrm{c}}} \frac{\delta F^{\prime \prime}}{A}=\frac{\Delta C^{\prime \prime}}{\omega_{\mathrm{c}}} \operatorname{Im}\left(\hat{H}\left(\omega_{\mathrm{c}}\right)\right)(V-\phi)^{2}
$$

where $F^{\prime \prime}$ is the out-of-phase force acting on the cantilever. The voltage-normalized dissipation $\gamma_{s} \propto \operatorname{Im}\left(\hat{H}\left(\omega_{c}\right)\right)$ plotted in Figure $4 \mathrm{a}$ is related to $\Gamma_{\mathrm{s}}$ through the equation $\Gamma_{\mathrm{s}}=\gamma_{\mathrm{s}}(V-\phi)^{2}$. The BLDS measurements of Figures 3, 7, and 10 are frequencyshift measurements that probe the response of the sample to an oscillating applied voltage

$$
\begin{aligned}
& \Delta f_{\mathrm{BLDS}}\left(\omega_{\mathrm{m}}\right)=-\frac{f_{\mathrm{c}} V_{\mathrm{m}}{ }^{2}}{16 k}\left[C_{\mathrm{q}}^{\prime \prime}+\Delta C^{\prime \prime} \operatorname{Re}\left(\hat{H}\left(\omega_{\mathrm{m}}+\omega_{\mathrm{c}}\right)\right.\right. \\
& \left.\left.+\hat{H}\left(\omega_{\mathrm{m}}-\omega_{\mathrm{c}}\right)\right)\right]\left|\hat{H}\left(\omega_{\mathrm{m}}\right)\right|^{2}
\end{aligned}
$$

where $\omega_{\mathrm{m}}$ and $V_{\mathrm{m}}$ are the frequency and amplitude, respectively, of the oscillating applied voltage and we have assumed that the amplitude modulation frequency $\omega_{\mathrm{am}}$ is much smaller than $\omega_{\mathrm{m}}$ (see Experimental Section in Supporting Information). The imaginary part of the transfer function $\hat{H}$ is significant only at the frequency $1 / \tau_{\text {fast }}$, where the real part of the transfer function starts to roll-off. The term in eq 7 containing the factors $\hat{H}\left(\omega_{c}-\right.$ $\left.\omega_{\mathrm{m}}\right)$ and $\hat{H}\left(\omega_{\mathrm{c}}+\omega_{\mathrm{m}}\right)$ is small as indicated by the BLDS spectra obtained at low light intensity over $\mathrm{SnO}_{2}$ and $\mathrm{TiO}_{2}$, Figure 3, where the majority of the response rolls off at $\omega_{\mathrm{m}} \ll \omega_{\mathrm{c}}$. We conclude that the BLDS measurement primarily measures the in-phase forces at the modulation frequency. The voltagenormalized frequency shift $\alpha$ plotted in Figures 3, 7, and 10 is related to $\Delta f_{\text {BLDS }}$ by

$$
\alpha=\frac{\Delta f_{\mathrm{BLDS}}\left(\omega_{\mathrm{m}}\right)}{V_{\mathrm{m}}^{2}}
$$

Figure 1 summarizes the experimental set-up and the measured quantity in each of the three different scanning probe measurements employed in this manuscript.

3.2. Experimental Findings. We now present data acquired on the FAMACs samples prepared on a range of substrates. All of the substrates $\left(\mathrm{TiO}_{2}, \mathrm{SnO}_{2}, \mathrm{NiO}\right.$, and ITO) are planar structures. The FAMACs thickness was $\sim 700 \mathrm{~nm}$; the thickness of ETL/hole transport layer was $\sim 40 \mathrm{~nm}$ with an average roughness of $\sim 10 \mathrm{~nm}$, and the thickness of the ITO was $\sim 100 \mathrm{~nm}$ with an average roughness of $\sim 2 \mathrm{~nm}$. The samples were illuminated from the top. The high absorption coefficient of the perovskite film means that electron and hole generation was confined to the top $\sim 200 \mathrm{~nm}$ of the sample, a distance significantly smaller than the $700 \mathrm{~nm}$ thickness of the FAMACs layer. Figure 2 shows device-performance data for a representative FAMACs film prepared on a $\mathrm{TiO}_{2}$ substrate; these data demonstrate the high quality of the films used in this study.

Figure 3 shows BLDS data (BLDS, ${ }^{50}$ Figure 1a) acquired of films prepared on $\mathrm{TiO}_{2}, \mathrm{SnO}_{2}$, ITO, and $\mathrm{NiO}$ substrates (see the Experimental Section in Supporting Information). In Figure 3, a decrease in $\alpha$ at large voltage-modulation frequency $\omega_{\mathrm{m}}$ indicates qualitatively that not all of the sample charge is able to follow the modulated tip charge. In our impedance model of the tip-sample interaction, Figure S2, this decrease is attributed to the RC roll-off of the tip-sample circuit. A light-dependent a)
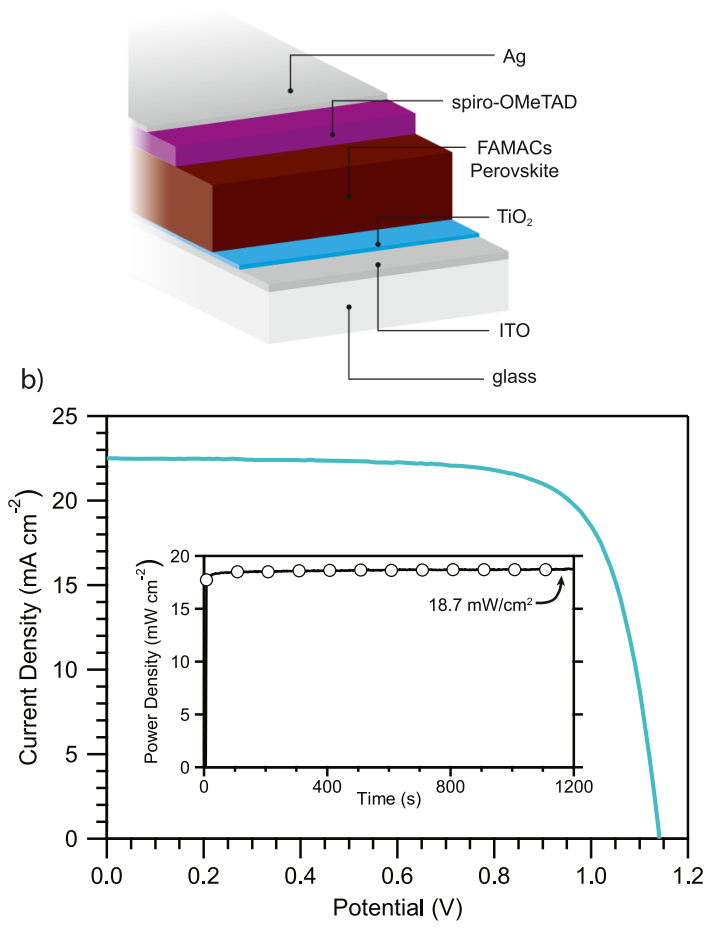

Figure 2. (a) Control perovskite solar cells were fabricated with the $\mathrm{TiO}_{2} /$ FAMACs/spiro-OMeTAD/Ag architecture depicted in the schematic. (b) Reverse scan (scan taken from open-circuit voltage, $V_{\mathrm{OC}}$, to short-circuit current, $\left.J_{\mathrm{SC}}\right)$ current density-voltage $(J-V)$ curve taken for a device with the architecture depicted in (a). From the reverse $J-V$ scan, the $V_{\mathrm{OC}}, J_{\mathrm{SC}}$, fill factor, and power conversion efficiency were measured to be $1.141 \mathrm{~V}, 22.49 \mathrm{~mA} / \mathrm{cm}^{2}, 0.744$, and $19.1 \%$. The inset shows the power density of the device monitored at a constant bias of $0.94 \mathrm{~V}$ over the course of $1200 \mathrm{~s}$, which was found to stabilize at $18.7 \%$ efficiency.

change in the roll-off frequency is consistent with sample conductivity increasing with increasing light intensity or, in other words, a decrease in the time constant $\tau_{\text {fast }}$ with light. In Figure 3, we clearly see a roll-off of the $\alpha$ versus $\omega_{\mathrm{m}}$ curves that depends on the light intensity in the case of electron-acceptor substrates $\left(\mathrm{TiO}_{2}\right.$ and $\left.\mathrm{SnO}_{2}\right)$, whereas in the case of the NiO(hole acceptor) and ITO-substrate samples, $\alpha$ is independent of both $\omega_{\mathrm{m}}$ and light intensity.

For the rest of this section of the manuscript, we compare the light and frequency dependence of the conductivity in the $\mathrm{TiO}_{2}$ and $\mathrm{SnO}_{2}$-substrate samples. Both samples show a lightdependent roll-off of the dielectric response. However, some significant differences can also be seen:

1 In the dark, the $\mathrm{SnO}_{2}$-substrate sample is more conductive than the $\mathrm{TiO}_{2}$-substrate sample as seen by their dark BLDS response curves.

2 The conductivity of the $\mathrm{SnO}_{2}$-substrate sample is more strongly affected by light than that of the $\mathrm{TiO}_{2}$-substrate sample; the roll-off moves to higher frequencies for the same light intensity for the $\mathrm{SnO}_{2}$-substrate sample compared to the $\mathrm{TiO}_{2}$-substrate sample.

These light-dependent conductivity effects can be confirmed through quasi-steady-state measurements of the cantilever frequency shift $(\Delta f)$ versus applied tip voltage $\left(V_{\mathrm{ts}}\right)$ and cantilever amplitude $(A)$ versus applied tip voltage (Figure $1 \mathrm{~b}$ ). In these measurements, the cantilever is driven using constant- 
a)

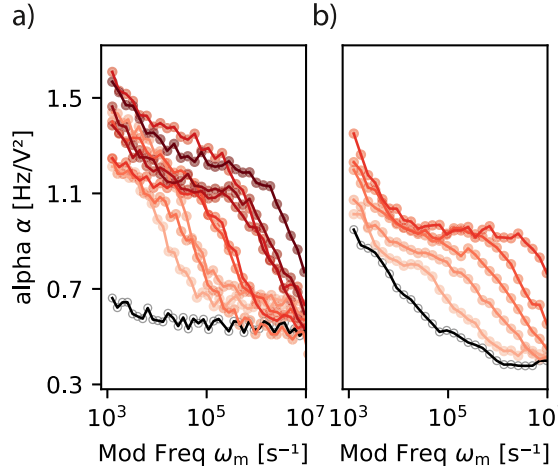

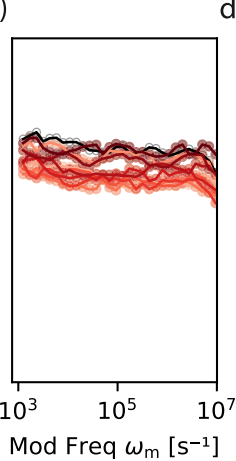

d)

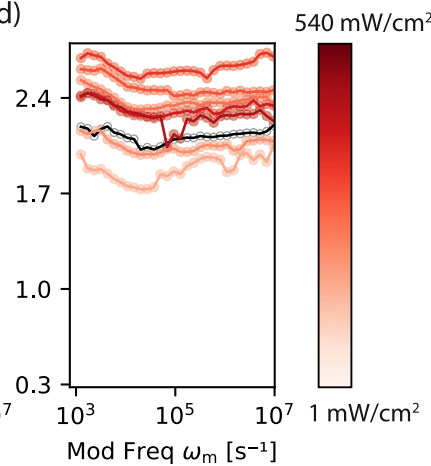

Figure 3. Distinct BLDS curves seen in FAMACs thin films grown on (a) $\mathrm{TiO}_{2}$, (b) $\mathrm{SnO}_{2}$, (c) ITO, and (d) NiO. Curves are colored according to the applied light intensity (see right hand legend) and vertically offset by 0.05 for clarity. For reference, BLDS curve in the dark is shown in open black circles. Experimental parameters: modulation voltage $V_{\mathrm{m}}=6 \mathrm{~V}, \lambda=639 \mathrm{~nm}$, tip-sample separation $h=200 \mathrm{~nm}$, except for the $\mathrm{TiO}_{2}$-substrate sample where $h=150 \mathrm{~nm}$.

amplitude resonant excitation, and the cantilever amplitude and frequency shift are recorded at each applied $V_{\text {ts. }}$ By fitting the measured frequency shift and amplitude data to eqs S4 and S9, respectively-see Figure S3 for representative curves and Section S3 for calculation details-we can calculate the curvature $\left(\alpha_{0}\right)$ change and a voltage-normalized sample-induced dissipation constant $\left(\gamma_{\mathrm{s}}\right)$. These values are not affected by the tip voltage sweep width; the large wait time $(500 \mathrm{~ms})$ employed at each applied tip voltage ensures that the measured response is a steady-state response.

Figure $4 \mathrm{a}$ shows the sample-induced dissipation measured through the amplitude-voltage method. In this measurement, we

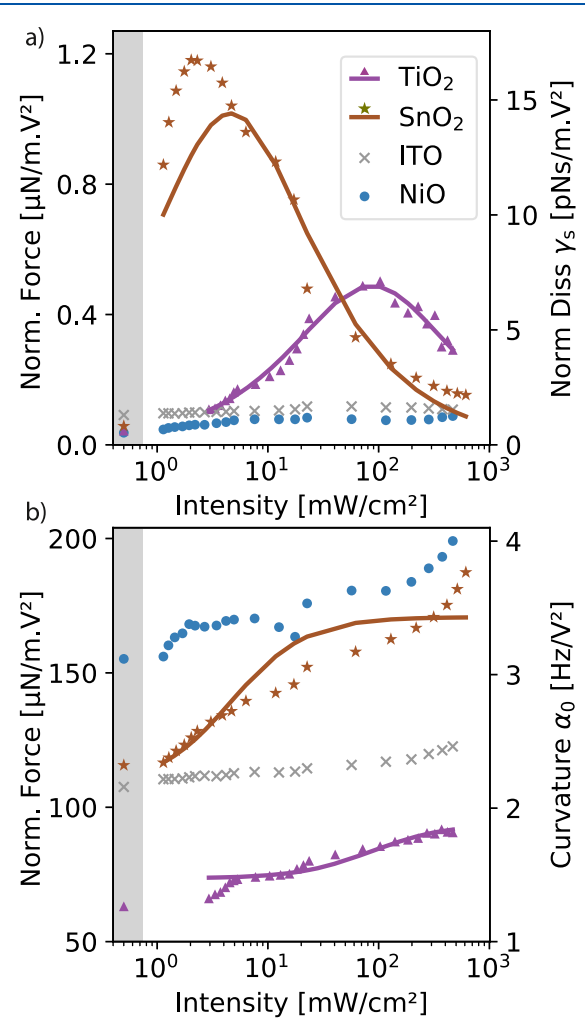

Figure 4. Normalized (a) out-of-phase (dissipation) (b) in-phase (curvature) force for FAMACs films on different substrates. Shaded points indicate values in the dark. Solid lines show a fit to the impedance model described in ref 35. Experimental parameters: $\lambda=639 \mathrm{~nm}, h=$ $200 \mathrm{~nm}, A_{0}=45 \mathrm{~nm}, V_{\mathrm{ts}}=-4$ to $4 \mathrm{~V}$ (bipolar sweeps). are sensitive to the out-of-phase response of the sample at the cantilever frequency. Figure S4 illustrates the predicted dependence of the curvature and sample-induced dissipation on light intensity. A nonlinear increase in dissipation which reaches a maximum and then decreases with light intensity can be explained by the existence of a time constant $\tau_{\text {fast }}$ that increased monotonically with light intensity. At high light intensities, the sample reaches its high-conductivity state. When $\tau_{\text {fast }}$ is less than $\omega_{\mathrm{c}}=2 \mu \mathrm{s}$, most of the sample charge responds instantaneously to changes in the tip position, leading to a decrease in the out-of-phase force acting on the cantilever and a reduction in sample-induced dissipation. We see for both the $\mathrm{TiO}_{2}$-substrate sample and the $\mathrm{SnO}_{2}$-substrate sample that dissipation reached a maximum before decreasing when the light intensity was increased monotonically. Figure $4 \mathrm{~b}$ shows that, concomitant with a dissipation peak, there is a nonlinear change in the in-phase response at the cantilever frequency, observed as a change in the curvature of the frequency shift versus applied tip voltage parabola $\left(\alpha_{0}\right)$.

The data of Figure 4, which primarily measure sample response at a single frequency $\left(\omega_{c}\right)$, corroborate the data of Figure 3 which show the sample response at multiple frequencies. The solid lines in Figure 4 are a fit to a one-timeconstant impedance model described in ref 35 and summarized in Section 3.1. The model qualitatively explains the seemingly anomalous peak in sample-induced dissipation versus light intensity data over both $\mathrm{TiO}_{2}$ and $\mathrm{SnO}_{2}$. The one-time-constant model only qualitatively describes the charge dynamics in the $\mathrm{SnO}_{2}$-substrate sample; adding further electrical components to the sample-impedance model, justified by the double roll-off seen in the Figure $3 b$ data, would improve the $\mathrm{SnO}_{2}$-substrate fits in Figure 4.

We observed the dynamics of $\tau_{\text {fast }}$ in real time through two different methods. In Figure 5a, we show how the dissipation changes for the $\mathrm{TiO}_{2}$-substrate sample for different light intensities. Here, we inferred sample-induced dissipation by measuring changes in the quality factor of the cantilever through a ring-down measurement (Figure 1c and Section S4). The recovery of dissipation clearly had two distinct timescales-a fast component and a slow component. In Figure 5a,b, when the light was switched on, there was a large and prompt ( $\leq 100 \mathrm{~ms}$ ) increase in dissipation followed by a small and much slower increase that lasted for $10 \mathrm{~s}$ or longer. The presence of the slow component was especially clear when the light intensity was greater than the light intensity giving the maximum dissipation. 

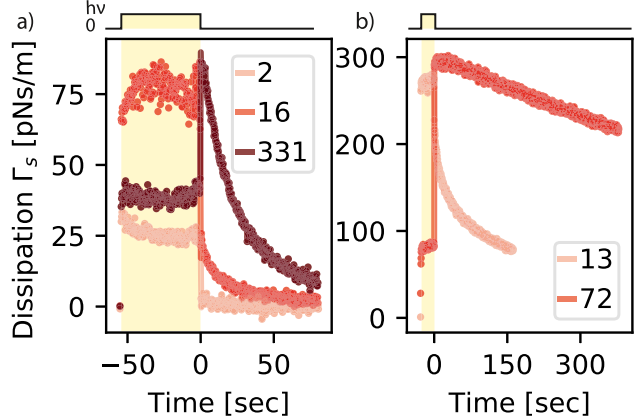

Figure 5. Dissipation recovery in the dark is substrate-dependent. Dissipation vs time for FAMACs film on (a) $\mathrm{TiO}_{2}$ and (b) $\mathrm{SnO}_{2}-$ substrate. The indicated illumination intensity (in $\mathrm{mW} / \mathrm{cm}^{2}$ ) was turned off at $t=0$ s. Experimental parameters: $V_{\mathrm{ts}}=-4 \mathrm{~V}, T=292 \mathrm{~K}$, (a) $\lambda=535 \mathrm{~nm}, h=175 \mathrm{~nm}$, (b) $\lambda=639 \mathrm{~nm}, h=200 \mathrm{~nm}$.

Whether the dissipation increased or decreased when the light was switched off depended on the value that $\tau_{\text {fast }}$ (i.e. sample conductivity) reached during the light-on period. At low light intensities (2.06 and $15.6 \mathrm{~mW} \mathrm{~cm}$ for the $\mathrm{TiO}_{2}$-substrate sample, Figure $5 \mathrm{a}$, and $13 \mathrm{~mW} \mathrm{~cm} \mathrm{~cm}^{-2}$ for the $\mathrm{SnO}_{2}$-substrate sample, Figure 5b), the dissipation $\Gamma_{\mathrm{s}}$ decreased when the light was switched off, indicating that $\tau_{\text {fast }}$ was $\geq 2 \mu \mathrm{s}$. On the other hand, the initial increase in $\Gamma_{s}$ when the light was switched off for the $331 \mathrm{~mW} \mathrm{~cm}^{-2}$ dataset in Figure $5 \mathrm{a}$ and the $72 \mathrm{~mW} \mathrm{~cm}^{-2}$ dataset in Figure $5 \mathrm{~b}$ is consistent with a light-on $\tau_{\text {fast }}$ being $\leq 2 \mu \mathrm{s}$. In such a case, when the light was switched off, the $\Gamma_{\mathrm{s}}$ promptly increased in $\leq 200 \mathrm{~ms}$ as $\tau_{\text {fast }}$ approached the value of $2 \mu \mathrm{s}$. Subsequently, $\Gamma_{\mathrm{s}}$ gradually decreased over 10 's of seconds as $\tau_{\text {fast }}$ became $\geq 2 \mu$ s.

In Figure 5b, we show a time-resolved light-induced dissipation measurement for the $\mathrm{SnO}_{2}$-substrate sample. The slow part of the recovery of dissipation was extremely slow $(>500 \mathrm{~s})$ at room temperature. This slow recovery indicates that the $\mathrm{SnO}_{2}$-substrate sample retained its conductive state for a much a longer time than did the $\mathrm{TiO}_{2}$-substrate sample. Interestingly, the slow time constant for dissipation recovery showed a dependence on the presoak intensity. As the light intensity increased, the dissipation recovery time constant became slower. The underlying process responsible for the dissipation recovery is thus light-intensity-dependent. The prompt recovery in conductivity was too fast to resolve, limited by the $100 \mathrm{~ms}$ time resolution of the ringdown measurement.

In Figure 6a, we show the temperature dependence of the slow part of the dissipation recovery. In Figure $6 \mathrm{~b}$, we plot the calculated dissipation-recovery time constant $\left(\tau_{\Gamma}\right)$ for the data in (a) versus temperature. The slow part of the dissipation recovery is activated with an activation energy $E_{\mathrm{a}}=0.58 \pm 0.07 \mathrm{eV}$ for the $\mathrm{TiO}_{2}$-substrate sample. For the $\mathrm{SnO}_{2}$-substrate sample, the slow part of the dissipation recovery did not show an appreciable change in the accessible $300-315 \mathrm{~K}$ temperature window (Figure S9). The dissipation recovery of the $\mathrm{SnO}_{2}$-substrate sample was much slower than $\mathrm{TiO}_{2}$-substrate sample at room temperature, implying $E_{\mathrm{a}} \geq 0.58 \mathrm{eV}$.

To further show the presence of two distinct recovery timescales, we examined the fixed-frequency dielectric response for the $\mathrm{TiO}_{2}$-substrate sample (Figure 7). Here, we illuminate the sample and measure the time-resolved dielectric response at a fixed modulation frequency $\left(\omega_{\mathrm{m}}\right)$. The response at each $\omega_{\mathrm{m}}$ corresponds to the in-phase force at that modulation frequency. By doing the measurement at different modulation frequencies,
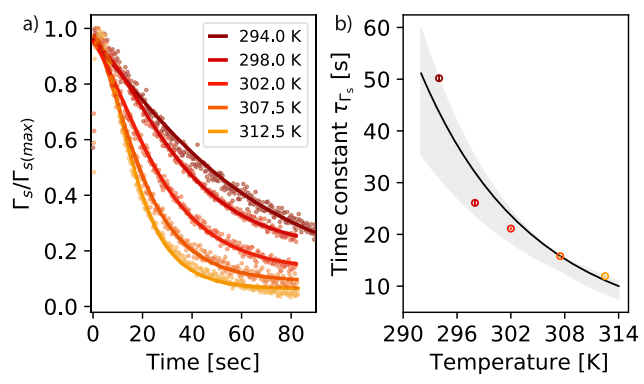

Figure 6. Dissipation recovery over the $\mathrm{TiO}_{2}$-substrate sample is temperature-dependent. (a) Dissipation recovery transients in the dark after a period of continuous illumination. (b) Time constant for dissipation recovery $\Gamma_{s}$ recovery vs temperature with error bars calculated from the fits in (a). Error bars are small on the $y$-axis scale. The shaded region represents two standard deviations for a weighted least squares fit to an exponential model $\tau_{\Gamma}(T)=A^{-1} \exp \left(E_{\mathrm{a}} / k_{\mathrm{B}} T\right)$. The best fit parameters with two standard deviation error bars were $E_{\mathrm{a}}=0.58$ $\pm 0.07 \mathrm{eV}$ and $A=4.9 \pm 1.0 \times 10^{2} \mathrm{~s}^{-1}$. Experimental parameters: $V_{\mathrm{ts}}=$ $-4 \mathrm{~V}, I_{h \nu}=292 \mathrm{~mW} / \mathrm{cm}^{2}, t_{\text {soak }}=27 \mathrm{~s}, h=150 \mathrm{~nm}, \lambda=639 \mathrm{~nm}$.
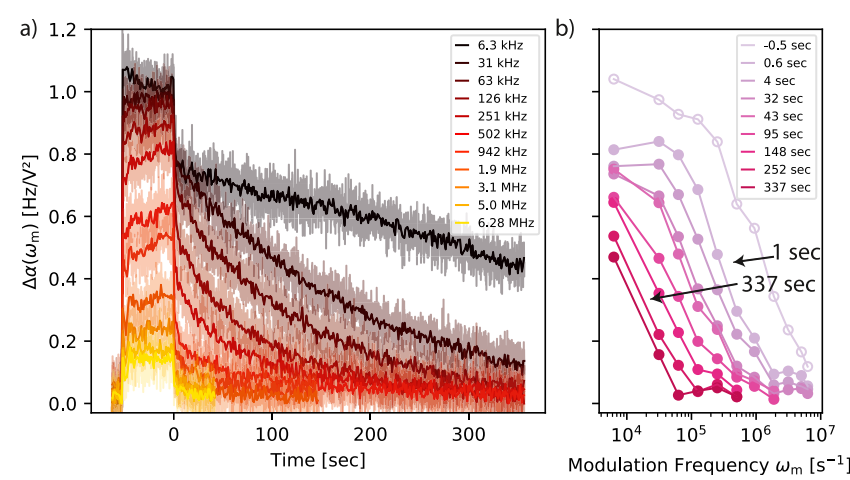

Figure 7. Dielectric response for the $\mathrm{TiO}_{2}$-substrate sample recovers on multiple timescales. See legend for modulation frequency. (a) Dielectric response vs time measured at the given, fixed modulation frequency $\omega_{\mathrm{m}}$. Large bandwidth (shaded) and $1 \mathrm{~s}$ running average (solid line). (b) Deduced dielectric response curves at various time offsets from the data in (a). Experimental parameters: $I_{h \nu}=292 \mathrm{~mW} /$ $\mathrm{cm}^{2}, h=150 \mathrm{~nm}, V_{\mathrm{m}}=4 \mathrm{~V}, \lambda=639 \mathrm{~nm}$.

we can visualize the time evolution of the full dielectric response curve in the dark after the light was turned off. Comparing the reconstructed dielectric response curves for time just before switching off the light (open circles) and $1.1 \mathrm{~s}$ after switching off the light (closed circles) shows a fast $(<1 \mathrm{~s})$ decrease in the rolloff frequency (i.e., a decrease in sample conductivity). This fast decrease was followed by a slow decrease lasting 100's of seconds before the dark state is reached. Thus, sample conductivity was decreasing on multiple distinct timescales in the dark. While the dielectric response curve measurement produces a more comprehensive picture of the conductivity recovery compared to the single-shot ring-down measurements, it is an inherently slower measurement than the ring-down measurement and is potentially affected by hysteresis because it requires a long resting time (600 $\mathrm{s}$ between each measurement).

We attribute changes in dissipation and the BLDS response to changes in sample resistance $R_{\mathrm{s}}$ (or conductivity) rather than sample capacitance $C_{s}$. In Figures $3 \mathrm{a}, \mathrm{b}$ and 7 , the high frequency response, determined by the ratio $C_{t} /\left(C_{s}+C_{t}\right)$, is independent of the light intensity. The similar high frequency response implies that $C_{s}$ does not depend strongly on the light intensity. Therefore, we can make the approximation that changes in the 
BLDS response primarily reflect changes in the sample resistance or, equivalently, sample conductivity. In a mixed ionic-electronic conductor, one might expect $R_{\mathrm{s}}$ to report on changes in the ambipolar resistance (or conductivity) and the measured dynamics of the resistance changes would be determined by the slowest diffusing species. ${ }^{74}$ Using a more accurate transmission-line model of sample impedance, we show below in Section 4.3 that our electric force microscope measurements are probing the total sample conductivity (eq 23a).

To verify that the tip electric field is not the cause of the slow dissipation recovery, we switched off the tip voltage during acquisition of the dissipation recovery transients for different durations of time (Figure 8). We find negligible differences in
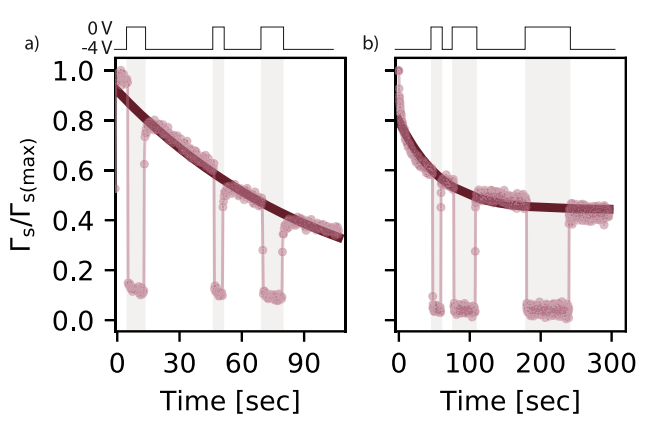

Figure 8. Recovery of the dissipation in the dark is unaffected by tip voltage $V_{\mathrm{ts}}$ for FAMACs films on (a) $\mathrm{TiO}_{2}$ and (b) $\mathrm{SnO}_{2}$. Tip voltage is turned to $V_{\mathrm{ts}}=0 \mathrm{~V}$ for different durations of time during dissipation recovery. Solid lines are fit to a simple exponential model for dissipation recovery. Experimental parameters: (a) presoak $I_{h \nu}=292 \mathrm{~mW} / \mathrm{cm}^{2}, V_{\mathrm{ts}}$ $=-4 \mathrm{~V}, h=150 \mathrm{~nm})(\mathrm{b})$ presoak $I_{h \nu}=5 \mathrm{~mW} / \mathrm{cm}^{2}, \lambda=639 \mathrm{~nm}, V_{\mathrm{ts}}=-4$ $\mathrm{V}, h=200 \mathrm{~nm})$, typical $\Gamma_{\max }=100 \mathrm{pN} \mathrm{s} / \mathrm{m}$.

the dissipation recovery transient when the tip voltage is switched off. We conclude that we are passively observing fluctuations in the sample whose dynamics are unaffected by the tip charge, that is we are operating in the linear-response regime of fluctuation-dissipation theorem. This finding indicates that $\tau_{\text {fast }}$ represents sample conductivity that continues to relax irrespective of the tip electric field at the surface. This experimental result also rules out that changes in the conductivity are due to tip-induced charging and discharging of the interfacial redistribution of electronic and ionic charges at the perovskite-substrate interface.

Lead halide perovskites are worse thermal conductors compared to many organic semiconductors and at normal solar cell operating conditions, thermal-gradient-induced ion migration away from the light source due to the Soret effect is a possibility. ${ }^{75}$ However, we can rule out temperature variations induced due to light as the main cause of the slow dissipation recovery. The slow recovery is evident at even very modest light intensity of $13 \mathrm{~mW} / \mathrm{cm}^{2}$ in Figure $5 \mathrm{a}$ and $15 \mathrm{~mW} / \mathrm{cm}^{2}$ in Figure $5 \mathrm{~b}$. Following the analysis of photothermal effects presented in ref 67 , even $300 \mathrm{~mW} / \mathrm{cm}^{2}$ would cause $<1 \mathrm{~K}$ change in temperature. Additional analysis of the data presented in Figure 3 is provided in Figures S10 and S11 and shows that $\tau_{\text {fast }}$ essentially decreases logarithmically with light intensity $I\left(\tau_{\text {fast }} \propto\right.$ $\left.(\log I)^{-1}\right)$. Photothermal effects would be inconsistent with this experimental result.

We next measure the effect of significantly reduced ion motion on the dynamics of sample conductivity. Several reports suggest that, in a similar temperature range $(233 \mathrm{~K})$, the effect of ion motion on measurements can be significantly reduced or eliminated by cooling the sample. This reduction manifests itself in device measurements as a reduced hysteresis in $J V$ curves. $^{76,77}$ This motion-reduction hypothesis was investigated here by measuring dissipation recovery dynamics at a low temperature (233 K). In Figure 9, we see that the dissipation versus light

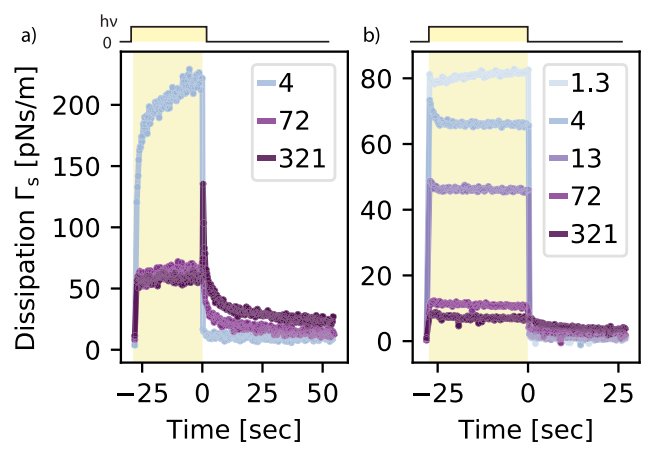

Figure 9. Slow dynamics of dissipation recovery are suppressed at 233 $\mathrm{K}$. Low-temperature dissipation recovery at selected light intensities (in $\mathrm{mW} / \mathrm{cm}^{2}, \lambda=639 \mathrm{~nm}$ ) for FAMACs film on (a) $\mathrm{TiO}_{2}$ and (b) $\mathrm{SnO}_{2}$.

intensity showed a similar behavior to the room temperature measurements of Figure 5 for the duration of illumination. This finding is further corroborated by BLDS measurements at a fixed light intensity taken at different temperatures for the $\mathrm{SnO}_{2}$ substrate sample. These data show that the value of $\tau_{\text {fast }}$ in $\mathrm{SnO}_{2}$ is unaffected by temperature (Figure 10) and $\tau_{\text {fast }}$ is decreased

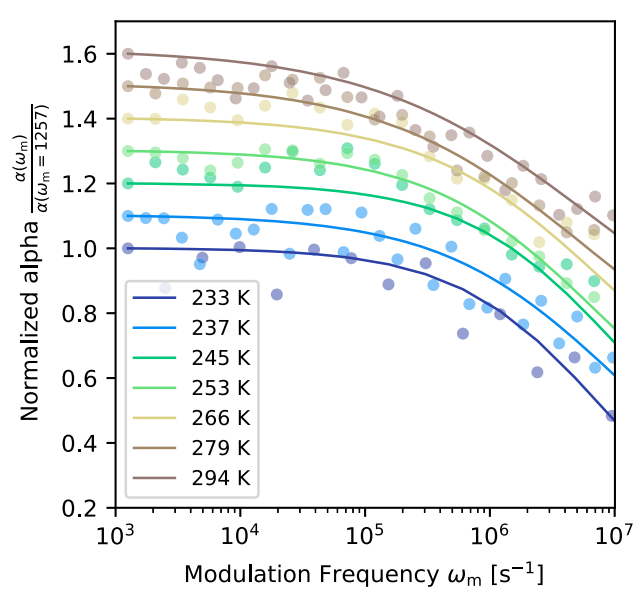

Figure 10. Qualitatively similar roll-off frequency for the BLDS curves shows minimal effect of temperature on the light-dependent conductivity. Normalized BLDS spectra for $\mathrm{SnO}_{2}$-substrate sample taken at various temperatures at the same light intensity $\left(I_{h \nu}=13 \mathrm{~mW} /\right.$ $\mathrm{cm}^{2}, \lambda=639 \mathrm{~nm}$ ) during gradual heating from $T=233 \mathrm{~K}$ to $T=294 \mathrm{~K}$ offset by 0.1 . Solid lines are a fit to a one time constant low pass filter and are presented as a guide only.

with increasing light intensity even as the temperature is lowered. Interestingly, there is essentially no slow recovery of dissipation when compared with room temperature (Figure 9). The absence of slow recovery dynamics is consistent with the hypothesis that the slow recovery (Figure 9) is determined by ion motion, which is substantially arrested at $233 \mathrm{~K}$. The total conductivity of the sample under illumination is dominated by the electronic carriers. ${ }^{19}$ The interaction of these electronic carriers with the slow moving ions determines the dynamics of 
the light-induced conductivity decrease when the light is switched off.

\section{DISCUSSION}

\subsection{Summary of Experimental Conductivity Findings.}

We have observed photo-induced changes in conductivity perturbing the electrostatic forces oscillating both in-phase and out-of-phase with the cantilever motion. Light-induced changes in the in-phase force leads to the frequency-shift effects seen in Figures $3,4 \mathrm{~b}$, and 7, while light-induced changes in the out-ofphase force causes the dissipation phenomena apparent in Figures 4a, 5, 6, and 8. Above we concluded from the highfrequency data in Figures $3 a, b$ and 7 that the light-dependence of both the dissipation and the BLDS response could be attributed to changes in sample resistance $R_{\mathrm{s}}$ (or conductivity $\sigma_{\mathrm{s}}$ ) rather than sample capacitance $C_{\mathrm{s}}$. Measuring dissipation thus allowed us to track changes in sample conductivity in real time as a function of light intensity and temperature. The resulting picture of sample conductivity dynamics was corroborated by monitoring the sample's dielectric spectrum in real time at selected frequencies.

We found that the observed sample conductivity in FAMACs

1. was substrate-dependent and

(a) was comparatively low in the dark and dependent on light intensity over $\mathrm{TiO}_{2}$ and $\mathrm{SnO}_{2}$ but

(b) was comparatively high in the dark and independent of light intensity over ITO and $\mathrm{NiO}$.

The light-dependent conductivity of FAMACs grown over $\mathrm{TiO}_{2}$ and $\mathrm{SnO}_{2}$ was studied in detail. We found that the conductivity in these samples

2. increased rapidly (<0.1 s) when light was applied;

3. had a steady-state value which increased with light intensity, with this increase being temperature-independent over $\mathrm{SnO}_{2}$;

4. retained its light-on value when the light was turned off at room temperature

(a) for 10's of seconds over $\mathrm{TiO}_{2}$ and

(b) for 100's of seconds over $\mathrm{SnO}_{2}$;

5. relaxed from a light-on value to a light-off value above room temperature with a rate that

(a) increased with increasing temperature over $\mathrm{TiO}_{2}$, with a large activation energy, $E_{\mathrm{a}}=0.58 \mathrm{eV}$, usually associated with vacancy or halide-ion motion but

(b) had no measurable temperature dependence over $\mathrm{SnO}_{2}$; and

6. relaxed from its light-on to its light-off value essentially instantaneously at a low temperature.

We wish to explain these findings microscopically. The first step in doing so is to consider the source of the observed conductivity.

4.2. Conductivity Sources. There are two obvious contributions to sample conductivity $\sigma_{\mathrm{s}}$ to consider-electronic and ionic. Light-dependent electronic conductivity is expected in a semiconductor like a lead-halide perovskite in which light absorption in the bulk creates free electrons and holes. If the conductivity is dominated by electronic conductivity then one would expect the conductivity to increase rapidly under illumination and be intensity-dependent, consistent with observation 1a. Further experiments show that the fast time constant is essentially linear in light intensity (Figures S10 and S11). When the light is turned off, however, the electronic conductivity should decay to its light-off value on the timescale of the carrier lifetime-nanoseconds to microseconds in leadhalide perovskites. ${ }^{7,78-82}$ Instead we find that the light-induced conductivity over $\mathrm{TiO}_{2}$ and $\mathrm{SnO}_{2}$ persisted for 10's to 100 's of seconds when the light was turned off.

The observed sample conductivity $\sigma_{\mathrm{s}}$ could alternatively be dominated by ionic conductivity. Perovskites are expected to have a high concentration of charged vacancies; ${ }^{1-3}$ the vacancy concentration depends on the electron Fermi level and on the chemical potential (i.e., the concentration) of the chemical species present during film growth. ${ }^{1,3}$ Prior studies have demonstrated that the electron Fermi level of the perovskite can moreover be altered by changing the work function of the substrate, ${ }^{11,13,83,84}$ with recent work demonstrating that the substrate can change the stoichiometry of the perovskite film as well. $^{85}$ On the basis of the observations of refs, ${ }^{11,13,83,84}$ we would expect a high halide-vacancy concentration in a perovskite grown over a hole-injecting substrate such as $\mathrm{NiO}$ or ITO, in agreement with the observed trends in the light-off conductivity, observation $1 \mathrm{~b}$. If the sample conductivity is dominated by ionic conductivity, however, we would not expect the ionic conductivity to be linearly proportional to light intensity and independent of temperature (observations 3 ), nor would we expect ionic conductivity to retain a memory of the light intensity for 10's to 100's of seconds in the dark (observations 3 and 4).

In summary, the observed conductivity has attributes of both electronic and ionic conductivity. Tirmzi and co-workers observed a similarly puzzling long-lived photo-induced conductivity in their related prior dissipation-microscopy experiments on $\mathrm{CsPbBr}_{3}$. They posited that photo-induced electrons and holes were being captured by charged vacancies existing in the film ${ }^{35}$

$$
\begin{aligned}
& \mathrm{V}_{\mathrm{Br}}^{\bullet}+\mathrm{e}^{\prime} \rightleftharpoons\left(\mathrm{V}_{\mathrm{Br}}^{\bullet} \cdots \mathrm{e}^{\prime}\right) \\
& \mathrm{Br}_{\mathrm{i}}^{\prime}+\mathrm{h}^{\bullet} \rightleftharpoons\left(\mathrm{Br}_{\mathrm{i}}^{\prime} \cdots \mathrm{h}^{\bullet}\right)
\end{aligned}
$$

The idea of a weakly trapped electron and hole, $\left(\mathrm{V}_{\mathrm{Br}}^{\bullet} \cdots \mathrm{e}^{\prime}\right)$ and $\left(\mathrm{Br}_{\mathrm{i}}^{\prime} \cdots \mathrm{h}^{\bullet}\right)$, respectively, was proposed as a way to simultaneously account for the conductivity's light dependence, memory, and large activation energy. The eq 9a proposal required the $\left(\mathrm{V}_{\mathrm{Br}}^{\bullet} \ldots\right.$ $\left.\mathrm{e}^{\prime}\right)$ and $\left(\mathrm{Br}_{\mathrm{i}}^{\prime} \cdots \mathrm{h}^{\bullet}\right)$ species to dominate the conductivity, which the ref 35 authors noted was seemingly at odds with the idea of a weakly trapped electron and hole. The notion that $\mathrm{V}_{\mathrm{Br}}^{\bullet}$ and $\mathrm{e}^{\prime}$ (or $\mathrm{Br}_{\mathrm{i}}^{\prime}$ and $\mathrm{h}^{\bullet}$ ) diffuse together as a unit is the central idea underlying the concept of ambipolar conductivity, although the authors of ref 35 did not employ this term. We will consider ambipolar conductivity in more detail shortly.

The hypothesis that we are observing ambipolar conductivity resolves some but not all of our puzzling conductivity observations. We need another key new idea. Since the work of Tirmzi et al., Kim, Maier, and co-workers ${ }^{19}$ have used multiple physical measurements to demonstrate that light induces a large enhancement in the ionic conductivity of methylammonium lead iodide. To explain this observation they proposed a reaction of photo-induced holes with neutral iodine atoms in the lattice that generates neutral interstitial iodines and charged, mobile iodine vacancies

$$
\mathrm{I}_{\mathrm{I}}^{\times}+\mathrm{h}^{\bullet} \rightleftharpoons \mathrm{I}_{\mathrm{i}}^{\times}+\mathrm{V}_{\mathrm{I}}^{\bullet}
$$

In their view, the application of light increases the concentration of holes, $\left[\mathrm{h}^{\bullet}\right]$, which shifts the eq 10 equilibrium to the right; this shift increases the concentration of $\mathrm{V}_{\mathrm{I}}^{\bullet}$ which in turn increases the ionic conductivity. That the halide-vacancy 
concentration depends on $\left[\mathrm{h}^{\bullet}\right]$ is expected, given the dependence of defect concentration on electron Fermi level. ${ }^{1,3,9}$ The significance of the Kim et al. data is that it experimentally demonstrates the existence of light-induced changes in ionic conductivity and quantifies the size of the effect. For our purposes, the eq 10 observation provides a better starting point for understanding our observations than does the eq 9a conjecture. To describe our further observations it is helpful to augment eq 10 to include both the holes and electrons created by light absorption

$$
\mathrm{I}_{\mathrm{I}}^{\times} \stackrel{h \nu}{\longrightarrow} \mathrm{I}_{\mathrm{I}}^{\times}+\mathrm{h}^{\bullet}+\mathrm{e}^{\prime} \rightleftharpoons \mathrm{I}_{\mathrm{i}}^{\times}+\mathrm{V}_{\mathrm{I}}^{\bullet}+\mathrm{e}^{\prime}
$$

Equation 11 indicates the presence, after illumination, of cationic vacancies and charge-compensating electrons, both of which are mobile. We should therefore formulate the sample's dielectric response in terms of its ambipolar conductivity. ${ }^{86}$

4.3. Ambipolar Conductivity. The relevance of ambipolar conductivity to understanding light-dependent phenomena in mixed ionic-electronic conductors such as metal halide perovskites is just becoming apparent. ${ }^{74}$ In our prior scannedprobe study of $\mathrm{CsPbBr}_{3}$, we modeled the sample as a resistor $R_{\mathrm{s}}$ and capacitor $C_{s}$ connected in parallel. The quantitative response of an ambipolar sample in an electric force microscope experiment has not, to our knowledge, been considered before. ${ }^{87}$ In order to ascertain the dependence of measured dissipation and frequency shift on the sample's electronic and ionic conductivity, in this section we apply a more physically accurate transmission-line model of the sample's dielectric response. $^{88}$

The starting point for modeling the response of a charged cantilever to a conductive sample is the transfer function in eq 1 , which may be simplified to read

$$
\hat{H}(\omega)=\frac{1}{1+\mathrm{j} \omega C_{\mathrm{tip}} Z_{\mathrm{s}}(\omega)}
$$

with $Z_{\mathrm{s}}(\omega)$ the sample impedance. The impedance of a mixed ionic-electronic conductor was first derived in detail for various electrode models by Macdonald ${ }^{89}$ but the derivation ignored space-charge regions near the contacts. A more tractable and generalizable transmission-line treatment of a mixed ionicelectronic conductor was introduced by Jamnik and Maier. ${ }^{88}$ Their approach has since been applied to calculate the impedance spectra of materials ranging from ion-conducting ceramics $^{90,91}$ to lead-halide perovskite photovoltaics. ${ }^{92,93}$ Let us use the impedance formula given in ref 88 (correctly written as eq 61 in ref 90) to calculate an approximate $Z_{\mathrm{s}}(\omega)$ for our sample.

In the ref 88 model, the sample is assumed to contain two mobile charged carriers, where the first species is ionic (charge $z_{\text {ion }}=1$, concentration $c_{\text {ion }}$, conductivity $\left.\sigma_{\text {ion }}\right)$ and the second species is electronic (charge $z_{\text {eon }}=1$, concentration $c_{\text {eon }}$, conductivity $\left.\sigma_{\text {eon }}\right)$. The associated ionic and electronic resistance is given by $R_{\text {ion }}=L / \sigma_{\text {ion }} A$ and $R_{\text {eon }}=L / \sigma_{\text {eon }} A$, respectively, with $L$ the sample thickness and $A$ the sample crosssectional area. Two other variables arise naturally in the transmission-line treatment. The first is the chemical capacitance $^{88}$

$$
C_{\text {chem }}=\frac{q^{2}}{k_{\mathrm{B}} T}\left(\frac{1}{z_{\text {ion }}{ }^{2} c_{\text {ion }}}+\frac{1}{z_{\text {eon }}{ }^{2} c_{\text {eon }}}\right)^{-1} A L
$$

with $q$ the electronic unit of charge, $k_{\mathrm{B}}$ Boltzmann's constant, and $T$ temperature. It is reasonable to assume that $c_{\text {ion }} \gg$ $c_{\text {eon }} j^{2,79,94,95}$ in this limit, $C_{\text {chem }} \approx q^{2} A L c_{\text {eon }} / k_{\mathrm{B}} T$, and the chemical capacitance is determined by the concentration of the electronic carriers alone. The second central variable is the ambipolar diffusion constant, defined as

$$
D_{\mathrm{a}}=\frac{k_{\mathrm{B}} T}{q^{2}} \frac{\sigma_{\text {ion }} \sigma_{\text {eon }}}{\left(\sigma_{\text {ion }}+\sigma_{\text {eon }}\right)}\left\{\frac{1}{z_{\text {ion }}{ }^{2} c_{\text {ion }}}+\frac{1}{z_{\text {eon }}{ }^{2} c_{\text {eon }}}\right\}
$$

which simplifies to

$$
D_{\mathrm{a}}=\frac{L^{2}}{\left(R_{\text {ion }}+R_{\text {eon }}\right) C_{\text {chem }}}
$$

In ref 88 the electrodes are assumed to be symmetric and described by a distinct interface impedance for ionic and electrical carriers

$$
\begin{aligned}
& Z_{\text {ion }}^{\perp}=\frac{R_{\text {ion }}^{\perp}}{1+j \omega R_{\text {ion }}^{\perp} C_{\text {ion }}^{\perp}} \\
& Z_{\text {eon }}^{\perp}=\frac{R_{\text {eon }}^{\perp}}{1+j \omega R_{\text {eon }}^{\perp} C_{\text {eon }}^{\perp}}
\end{aligned}
$$

with the subscript indicating the carrier and the superscript $\perp$ indicating that the resistance and capacitance are associated with the sample/electrode interface. We can rearrange Jamnik and Maier's central impedance result to read

$$
\begin{aligned}
& Z_{\mathrm{s}}(\omega)=Z_{\infty}+\left(Z_{0}-Z_{\infty}\right) \\
& \times \frac{R_{\text {ion }}+R_{\text {eon }}+2\left(Z_{\text {ion }}^{\perp}+Z_{\text {eon }}^{\perp}\right)}{R_{\text {ion }}+R_{\text {eon }}+2\left(Z_{\text {ion }}^{\perp}+Z_{\text {eon }}^{\perp}\right) \sqrt{\frac{j \omega \tau}{4}} \operatorname{coth} \sqrt{\frac{j \omega \tau}{4}}}
\end{aligned}
$$

with the low- and high-frequency limiting impedance given by

$$
\begin{aligned}
& \frac{1}{Z_{0}}=\frac{1}{R_{\text {ion }}+2 Z_{\text {ion }}^{\perp}}+\frac{1}{R_{\text {eon }}+2 Z_{\text {eon }}^{\perp}} \\
& Z_{\infty}=\frac{R_{\text {ion }} R_{\text {eon }}}{R_{\text {ion }}+R_{\text {eon }}}+2 \frac{Z_{\text {ion }}^{\perp} Z_{\text {eon }}^{\perp}}{Z_{\text {ion }}^{\perp}+Z_{\text {eon }}^{\perp}}
\end{aligned}
$$

and the time constant $\tau$ defined as

$$
\tau=\frac{L^{2}}{D_{\mathrm{a}}}=\left(R_{\text {ion }}+R_{\text {eon }}\right) C_{\text {chem }}
$$

Our sample has a bottom contact consisting of a grounded electrical conductor and a top contact consisting of an electrically biased tip-sample capacitor. The impedance of the tip-sample capacitor operating in series with the electrically ground sample is already captured in eq 12 . To capture the impedance of our sample in the transmission-line formalism, we assume that the electrodes (1) are Ohmic for the electronic carriers, $Z_{\text {eon }}^{\perp} \approx 0$, and $(2)$ are blocking for the ions, $R_{\text {ion }}^{\perp} \rightarrow \infty$ and consequently $Z_{\text {ion }}^{\perp} \approx 1 / \mathrm{j} \omega C_{\mathrm{ion}}^{\perp}$. Under these simplifying assumptions, $Z_{\infty}=R_{\text {ion }} R_{\text {eon }} /\left(R_{\text {ion }}+R_{\text {eon }}\right)$. In reality the sample's bottom face is metal-terminated while its top face is vacuum terminated; although the sample is not strictly symmetric, under our electrode assumptions the transmission-line impedance model should nevertheless give accurate guidance on what sample properties our scanned probe measurements are probing. Substituting for the expressions for $Z_{0}$ and $Z_{\infty}$ in the ion-blocking limit in eq 16 a and simplifying the result we obtain 


$$
Z_{\mathrm{s}} \approx \frac{R_{\text {ion }} R_{\text {eon }}}{R_{\text {ion }}+R_{\text {eon }}}\left\{1+\frac{1}{\sqrt{\frac{\mathrm{j} \omega}{\omega_{\text {chem }}}} \operatorname{coth} \sqrt{\frac{j \omega R_{\text {eon }}^{2}}{\omega_{\text {chem }} R_{\text {ion }}^{2}}}+j \frac{\omega}{\omega_{\text {ion }}}}\right\}
$$

with

$$
\omega_{\text {ion }} \equiv\left(\frac{1}{2} C_{\text {ion }}^{\perp} \frac{R_{\text {ion }}}{R_{\text {eon }}}\left(R_{\text {ion }}+R_{\text {eon }}\right)\right)^{-1}
$$

and

$$
\omega_{\text {chem }} \equiv\left(\frac{1}{4} C_{\text {chem }} \frac{R_{\text {ion }}{ }^{2}}{R_{\text {eon }}{ }^{2}}\left(R_{\text {ion }}+R_{\text {eon }}\right)\right)^{-1}
$$

As long as $\omega \gg \omega_{\text {chem }}$ or $\omega \gg \omega_{\text {ion }}$, the sample impedance $Z_{\mathrm{s}}(\omega)$ will be operating in the high frequency limit where $Z_{\mathrm{s}} \approx$ $Z_{\infty}$. The transfer function describing the tip-sample interaction in this high-frequency limit can be approximated as (Figure 11a)

$$
\hat{H}(\omega) \approx \frac{1}{1+j \omega \tau_{\text {tip }}}
$$

with

$$
\tau_{\text {tip }}=\omega_{\text {tip }}^{-1}=\frac{L}{A} \frac{C_{\text {tip }}}{\sigma_{\text {ion }}+\sigma_{\text {eon }}}
$$

a)
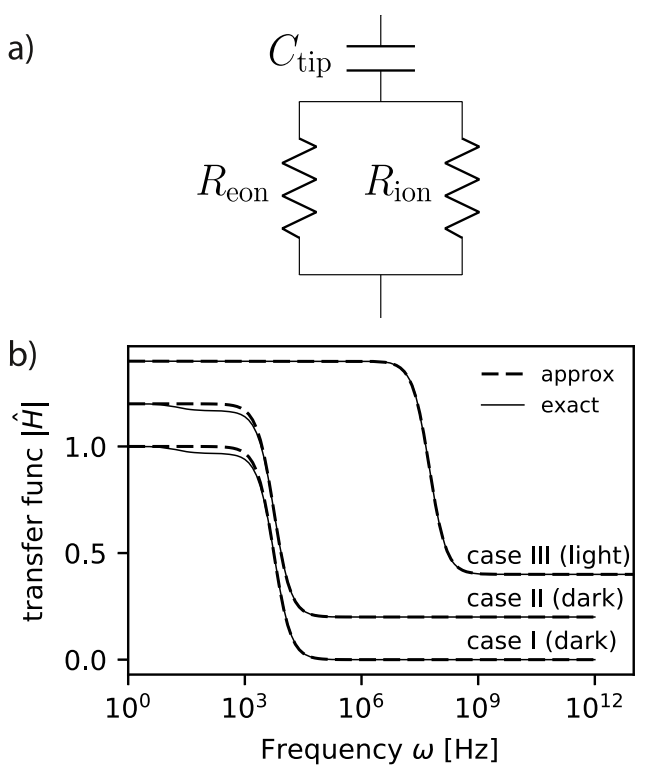

Figure 11. (a) Equivalent circuit representation of the impedance of a mixed ionic-electronic conductor in the high-frequency limit. (b) Approximate (dashed line) and exact (solid line) transfer function $|\hat{H}|$ for the representative case I (dark), case II (dark), and case III (light) sample properties given in Table 1 . In each case in (b), the transfer function has been offset by 0.2 for clarity.

Slightly surprisingly, the roll-off of $\hat{H}(\omega)$ depends not on the ambipolar conductivity but on the total conductivity, $\sigma_{\text {ion }}+\sigma_{\text {eon }}$.

We can check the validity of the approximate eq 23a transfer function by comparing with $\hat{H}(\omega)$ calculated using the full impedance expression of eq 20. To calculate the transfer function requires knowledge of $c_{\text {ion }}, c_{\text {eon }}, \sigma_{\text {ion }}, \sigma_{\text {eon }}, C_{\text {ion }}^{\perp}$ and $C_{\text {tip }}$. To our knowledge, no single study provides values for all these quantities for FAMACs. We therefore turn to the $\mathrm{CH}_{3} \mathrm{NH}_{3} \mathrm{PbI}_{3}$ literature for order-of-magnitude estimates of these quantities; see Table 1A. The dark $c_{\text {eon }}$ estimates vary from $5 \times 10^{9} \mathrm{~cm}^{-3}$ [case I (dark)] to $6 \times 10^{14} \mathrm{~cm}^{-3}$ [case II (dark)]. For $c_{\text {ion }}$ under illumination (case III), we expect the value to be similar or higher than the corresponding dark value. We calculated $R_{\text {eon }}$ and $R_{\text {ion }}$ from the ref 19 conductivities taking $L=700 \mathrm{~nm}$, the film thickness, and $A=7 \times 10^{-14} \mathrm{~m}^{2}$, our estimate of the cantilever-tip area. In Table $1 \mathrm{~A}$, we have linearly scaled the conductivities observed in ref 19 to account for the higher light intensities used in our measurements. The value of $C_{\text {chem }}$ (Table 1B) was calculated using eq 13 and the values for $c_{\text {ion }}$ and $c_{\text {eon }}$ given in Table $1 \mathrm{~A}$. We take $C_{\text {ion }}^{\perp}=\epsilon_{\mathrm{s}} \epsilon_{0} A / \lambda_{\mathrm{D}} \approx 1 \times 10^{-14} \mathrm{~F}$, where $\epsilon_{\mathrm{s}}=26^{96}$ is the static dielectric constant and $\lambda_{\mathrm{D}}=1.5 \mathrm{~nm}^{97}$ is the Debye length. We use $C_{\text {tip }}=1 \times 10^{-16} \mathrm{~F}$, a reasonable upperbound number taking in account the experimental tip-sample separation. ${ }^{69,98}$ Using Table $1 \mathrm{~A}, \mathrm{~B}$ values and the above estimates for $C_{\text {ion }}^{\perp}$ and $C_{\text {tip }}$, we obtain the frequencies $\omega_{\text {tip }}, \omega_{\text {ion }}$, and $\omega_{\text {chem }}$ given in Table $1 \mathrm{C}$.

We plot the resulting approximate and exact transfer function $\hat{H}(\omega)$ for two dark conditions and one light condition in Figure $11 \mathrm{~b}$. This exercise confirms that $Z_{\mathrm{s}} \approx Z_{\infty}$ is indeed a valid approximation. The effect of $\omega_{\text {ion }}$ on the transfer function $\hat{H}(\omega)$ is only significant when $\omega_{\text {ion }}$ or $\omega_{\text {chem }}$ is within an order of magnitude of $\omega_{\text {tip }}$. A slight breakdown of the eq 23a approximation can be seen in the Figure $11 \mathrm{~b}$ transfer-function plots for case I (dark) and II (dark) at low frequency. In most scenarios, this breakdown is unlikely to occur because $C_{\text {ion }}^{\perp} \gg$ $C_{\text {tip }}$ and in this limit $\omega_{\text {tip }} \gg \omega_{\text {ion }}$.

4.4. Explaining the Conductivity Findings. Now that we have established that the measurements in this manuscript probe total conductivity, we will look at how the concentrations of $h^{\bullet}$ and $\mathrm{V}_{\mathrm{I}}^{\bullet}$ and the eq 11 scheme can be used to rationalize differences in the conductivity and conductivity relaxation between different substrates.

We would expect the concentration of holes in the dark $\left[\mathrm{h}^{\bullet}\right]_{\text {dark }}$ (and therefore $\left[\mathrm{V}_{\mathrm{I}}^{\bullet}\right]_{\text {dark }}$ ) to be high over the ITO and $\mathrm{NiO}$ and low over $\mathrm{TiO}_{2}$ and $\mathrm{SnO}_{2} .{ }^{11,13,83,84}$ Observations $1 \mathrm{a}, 1 \mathrm{~b}$, and 3 follow from eq 10 and the assumption that $\left[\mathrm{h}^{\bullet}\right]_{\text {light }} \ll$ $\left[\mathrm{h}^{\bullet}\right]_{\text {dark }}$ over ITO and $\mathrm{NiO}$ while $\left[\mathrm{h}^{\bullet}\right]_{\text {light }} \gg\left[\mathrm{h}^{\bullet}\right]_{\text {dark }}$ over $\mathrm{TiO}_{2}$ and $\mathrm{SnO}_{2}$. A change in the sample conductivity due to the substrate is indirectly implied in the results of refs ${ }^{11,13,83,84}$ where the work function of the perovskite surface was shown to change as a function of substrate work function. Our data likewise show a substrate effect, only here we probe the conductivity directly. The high absorption coefficient of the perovskite means that electrons and holes are primarily generated in the top $\sim 200 \mathrm{~nm}$ of our $700 \mathrm{~nm}$-thick films. Possible processes that may exist and can directly or indirectly change the material and therefore the total conductivity include substrate-induced strain effects, ${ }^{99,100}$ substrate-dependent sample microstructure and stoichiometry, ${ }^{85}$ and heterogeneous doping. ${ }^{101}$ Our current results are largely inconsistent with heterogeneous doping effects. Substrate effects through heterogeneous doping are going to be limited to a thin layer near the perovskite-substrate interface and are more prominent when the substrate is mesoporous. In this layer, the concentration of both electronic and ionic charges is determined by the substrate perovskite interaction. ${ }^{101}$ This is inconsistent with the Figure 8 results and the thickness of the films $(700 \mathrm{~nm})$ used in our measurements.

Under illumination, the concentration of $h^{\bullet}$ is high; the forward reaction in eq 11 proceeds rapidly, creating charged vacancies and free electrons resulting in the promptly appearing 
Table 1. (A) Literature Values for Sample Properties Needed To Calculate (B) and (C)

\begin{tabular}{|c|c|c|c|c|c|c|c|c|}
\hline & \multirow[b]{2}{*}{ quantity } & \multirow[b]{2}{*}{ unit } & \multicolumn{2}{|c|}{ case I (dark) } & \multicolumn{2}{|c|}{ case II (dark) } & \multicolumn{2}{|c|}{ case III (light) } \\
\hline & & & value & refs & value & refs & value & refs \\
\hline \multirow[t]{4}{*}{ A } & $c_{\text {eon }}$ & $\mathrm{cm}^{-3}$ & $5 \times 10^{9}$ & 94 & $6 \times 10^{14}$ & 95 & $2 \times 10^{15}$ & 79 \\
\hline & $c_{\text {ion }}$ & $\mathrm{cm}^{-3}$ & $2 \times 10^{20}$ & 2 & $2 \times 10^{20}$ & 2 & $2 \times 10^{20}$ & \\
\hline & $\sigma_{\text {eon }}$ & $\mathrm{S} \mathrm{cm}^{-1}$ & $5 \times 10^{-9}$ & 19 & $5 \times 10^{-9}$ & 19 & $5 \times 10^{-4}$ & 19 \\
\hline & $\sigma_{\text {ion }}$ & $\mathrm{S} \mathrm{cm}^{-1}$ & $5 \times 10^{-8}$ & 19 & $5 \times 10^{-8}$ & 19 & $5 \times 10^{-5}$ & 19 \\
\hline B & $C_{\text {chem }}$ & $\mathrm{F}$ & $1.6 \times 10^{-21}$ & & $1.9 \times 10^{-16}$ & & $6.2 \times 10^{-16}$ & \\
\hline \multirow[t]{3}{*}{$\mathrm{C}$} & $\omega_{\text {chem }}$ & $\mathrm{Hz}$ & $1.0 \times 10^{3}$ & & $1.0 \times 10^{3}$ & & $3.0 \times 10^{6}$ & \\
\hline & $\omega_{\text {ion }}$ & $\mathrm{Hz}$ & 9.2 & & $1.2 \times 10^{8}$ & & $9.2 \times 10^{4}$ & \\
\hline & $\omega_{\text {tip }}$ & $\mathrm{Hz}$ & $5.6 \times 10^{3}$ & & $5.6 \times 10^{3}$ & & $5.6 \times 10^{7}$ & \\
\hline
\end{tabular}

light-dependent conductivity of observations 2 and 3. The relative similarity of the dependence of the conductivity on time, light, and temperature over $\mathrm{SnO}_{2}$ and $\mathrm{TiO}_{2}$ suggests to us that the light-on conductivity in $\mathrm{TiO}_{2}$ is also likely dominated by electronic conductivity. According to eq $23 \mathrm{~b}$, for the observed total conductivity to return to its light-off value, both $\sigma_{\text {ion }}$ and $\sigma_{\text {eon }}$ need to return to their dark values. Observation 4 is explained by the back reaction in eq 11 having a high activation energy and proceeding slowly. The differences in the timescale of the conductivity relaxation over $\mathrm{TiO}_{2}$ and $\mathrm{SnO}_{2}$, Observations $5 a$ and $5 b$, requires a difference in this activation energy or in the mobility of ions in the FAMACs grown on the two substrates. Christians and co-workers have reported a differences in the distribution of ions in aged devices incorporating $\mathrm{TiO}_{2} /$ FAMACs and $\mathrm{SnO}_{2}$ /FAMACs interfaces, as quantified by ToF-SIMS; ${ }^{30}$ these differences are consistent with the slower relaxation seen here over $\mathrm{SnO}_{2}$.

The fast conductivity relaxation seen at a low temperature, observation 6, seems prima facia at odds with the slow and activated recovery seen at room temperature, observations 4 and 5 . We should consider, however, that once generated, the iodine vacancy, $\mathrm{V}_{\mathrm{I}}^{*}$, and the neutral iodine interstitial defect, $\mathrm{I}_{\mathrm{i}}^{\times}$, are expected to diffuse away from each other (to maximize entropy). In mixed-halide perovskites, light has been shown to promote halide segregation and in these systems the rate of segregation depends on the light intensity. ${ }^{102,103}$ One might therefore expect the eq 11 back reaction underlying observations 4 and 5 to be diffusion-limited; in this limit the activation energy of the back reaction is the $E_{\mathrm{a}}$ governing $\mathrm{V}_{\mathrm{I}}^{\bullet}$ and $\mathrm{I}_{\mathrm{i}}^{\times}$diffusion. The $E_{\mathrm{a}}$ we observe over $\mathrm{TiO}_{2}$ is consistent with the activation energy measured for halide-vacancy motion in lead-halide perovskites. ${ }^{15,102,104}$ The activation energy observed is the activation energy for the total conductivity relaxation. This will in turn depend on the concentration electronic and ionic species, but also on their mobility. We note that the light intensity primarily determines the concentration of both ionic and electronic carriers and was kept constant for variable temperature measurements. While we are not directly probing the activation energy of ionic diffusion (and therefore the ionic mobility), it is the most likely term to change in the small temperature window used in the measurement. At low temperatures, we expect the vacancy diffusion to be suppressed and consequently might expect the back reaction to be now fast because the $V_{I}^{\bullet}$ and $I_{i}^{\times}$ species generated by the forward eq 11 reaction remain in close proximity. This prediction is indeed consistent with observation 6.

Subsequent reactions are also possible. On the basis of Minns et al.'s ${ }^{105} \mathrm{X}$-ray and neutron diffraction studies of $\left(\mathrm{CH}_{3} \mathrm{NH}_{3}\right)$ $\mathrm{PbI}_{3}$, for example, we expect the iodine interstitials to form stable interstitial $\mathrm{I}_{2}$ moieties. The concentration of these $\mathrm{I}_{2}$ moieties (and the coupled vacancy concentration) can be decreased by lowering the temperature. Additionally, theory predicts the iodine interstitial to be a hole trap, $\mathrm{I}_{\mathrm{i}}^{\times}+\mathrm{h}^{\bullet} \rightleftharpoons \mathrm{I}_{\mathrm{i}}^{\bullet}$. ${ }^{106}$ Such reactions and the decreased concentration of $\mathrm{I}_{2}$ moieties, if present, might likewise explain the significant differences in recovery seen over $\mathrm{TiO}_{2}$ and $\mathrm{SnO}_{2}$, observations $5 \mathrm{a}$ and $5 \mathrm{~b}$.

\section{CONCLUSIONS}

Here, we have used measurements of sample-induced dissipation and sample dielectric spectra, backed by a rigorous theory of the cantilever-sample interaction, ${ }^{35,67,69}$ to carry out time-resolved studies of photo-induced changes in the total conductivity of a mixed-species lead-halide perovskite semiconductor thin film prepared on a range of substrates. Comparison of low temperature and room temperature data and a transmission-line model analysis of mixed ionicelectronic conductivity reveals that the observed photo-induced changes in cantilever frequency and dissipation report on changes in total sample conductivity, $\sigma_{\text {ion }}+\sigma_{\text {eon }}$. This insight establishes scanning-probe BLDS measurements as a method for quantifying local photoconductivity in semiconductors and other photovoltaic materials.

In the FAMACs samples studied here, light-induced changes in total conductivity relaxed on a time scale of 10's to 100's of seconds, with an activation energy of $0.58 \mathrm{eV}$ over $\mathrm{TiO}_{2}$; such a large activation energy is generally attributed to ion/vacancy motion. ${ }^{15,102,104}$ We rationalized these findings using the idea of light-induced vacancies recently proposed by Kim et al. ${ }^{19}$ In addition to the seemingly puzzling light-induced conductivity behavior explored here, light-induced creation of vacancies may also explain other light-induced anomalous behavior seen in lead halide perovskites including memory effects. ${ }^{25}$

\section{ASSOCIATED CONTENT}

\section{Supporting Information}

The Supporting Information is available free of charge on the ACS Publications website at DOI: 10.1021/acs.jpcc.8b11783.

Experimental details regarding SPM; experimental details for Figure 4; spatial variation the BLDS response; representative atomic force microscopy images; steady state and transient surface potential; fit detail for Figure 6; effect of below band gap illumination on dissipation; and $\tau_{\Gamma_{\mathrm{s}}}$ for $\mathrm{SnO}_{2}$-substrate sample (PDF)

\section{AUTHOR INFORMATION}

\section{Corresponding Author}

*E-mail: jam99@cornell.edu. Faculty webpage: http:// chemistry.cornell.edu/john-marohn. Research group webpage: http://marohn.chem.cornell.edu. 


\section{ORCID}

Ali Moeed Tirmzi: 0000-0002-1697-0592

Jeffrey A. Christians: 0000-0002-6792-9741

Ryan P. Dwyer: 0000-0002-7439-1054

\section{Notes}

The authors declare no competing financial interest.

\section{ACKNOWLEDGMENTS}

A.M.T., R.P.D., and J.A.M. acknowledge the financial support of the U.S. National Science Foundation (grant DMR-1709879). J.A.C. was supported by the Department of Energy (DOE) Office of Energy Efficiency and Renewable Energy (EERE) Postdoctoral Research Award under the EERE Solar Energy Technologies Office administered by the Oak Ridge Institute for Science and Education (ORISE) for the DOE under DOE contract number DE-SC00014664.

\section{REFERENCES}

(1) Yin, W.-J.; Shi, T.; Yan, Y. Unusual Defect Physics in $\mathrm{CH}_{3} \mathrm{NH}_{3} \mathrm{PbI}_{3}$ Perovskite Solar Cell Absorber. Appl. Phys. Lett. 2014, 104, 063903.

(2) Walsh, A.; Scanlon, D. O.; Chen, S.; Gong, X. G.; Wei, S.-H. SelfRegulation Mechanism for Charged Point Defects in Hybrid Halide Perovskites. Angew. Chem., Int. Ed. 2014, 54, 1791-1794.

(3) Shi, T.; Yin, W.-J.; Hong, F.; Zhu, K.; Yan, Y. Unipolar Self-doping Behavior in Perovskite $\mathrm{CH}_{3} \mathrm{NH}_{3} \mathrm{PbBr}_{3}$. Appl. Phys. Lett. 2015, 106, 103902.

(4) Brandt, R. E.; Stevanović, V.; Ginley, D. S.; Buonassisi, T. Identifying Defect-Tolerant Semiconductors With High MinorityCarrier Lifetimes: Beyond Hybrid Lead Halide Perovskites. MRS Commun. 2015, 5, 265-275.

(5) Emara, J.; Schnier, T.; Pourdavoud, N.; Riedl, T.; Meerholz, K.; Olthof, S. Impact of Film Stoichiometry on the Ionization Energy and Electronic Structure of $\mathrm{CH}_{3} \mathrm{NH}_{3} \mathrm{PbI}_{3}$ Perovskites. Adv. Mater. 2015, 28, $553-559$.

(6) Kim, J.; Lee, S.-H.; Lee, J. H.; Hong, K.-H. The Role of Intrinsic Defects in Methylammonium Lead Iodide Perovskite. J. Phys. Chem. Lett. 2014, 5, 1312-1317.

(7) Stranks, S. D. Nonradiative Losses in Metal Halide Perovskites. ACS Energy Lett. 2017, 2, 1515-1525.

(8) Tress, W.; Yavari, M.; Domanski, K.; Yadav, P.; Niesen, B.; Correa Baena, J. P.; Hagfeldt, A.; Graetzel, M. Interpretation and Evolution of Open-Circuit Voltage, Recombination, Ideality Factor and Subgap Defect States During Reversible Light-Soaking and Irreversible Degradation of Perovskite Solar Cells. Energy Environ. Sci. 2018, 11, 151-165.

(9) Senocrate, A.; Yang, T.-Y.; Gregori, G.; Kim, G. Y.; Grätzel, M.; Maier, J. Charge Carrier Chemistry in Methylammonium Lead Iodide. Solid State Ionics 2018, 321, 69-74.

(10) Moore, D. T.; Sai, H.; Tan, K. W.; Smilgies, D.-M.; Zhang, W.; Snaith, H. J.; Wiesner, U.; Estroff, L. A. Crystallization Kinetics of Organic-Inorganic Trihalide Perovskites and the Role of the Lead Anion in Crystal Growth. J. Am. Chem. Soc. 2015, 137, 2350-2358.

(11) Miller, E. M.; Zhao, Y.; Mercado, C. C.; Saha, S. K.; Luther, J. M.; Zhu, K.; Stevanović, V.; Perkins, C. L.; van de Lagemaat, J. SubstrateControlled Band Positions in $\mathrm{CH}_{3} \mathrm{NH}_{3} \mathrm{PbI}_{3}$ Perovskite Films. Phys. Chem. Chem. Phys. 2014, 16, 22122-22130.

(12) Schulz, P.; Whittaker-Brooks, L. L.; MacLeod, B. A.; Olson, D. C.; Loo, Y.-L.; Kahn, A. Electronic Level Alignment in Inverted Organometal Perovskite Solar Cells. Adv. Mater. Interfaces 2015, 2, 1400532.

(13) Olthof, S.; Meerholz, K. Substrate-dependent Electronic Structure and Film Formation of $\mathrm{MAPbI}_{3}$ Perovskites. Sci. Rep. 2017, $7,40267$.

(14) Ono, L. K.; Qi, Y. Research Progress on Organic-Inorganic Halide Perovskite Materials and Solar Cells. J. Phys. D: Appl. Phys. 2018, 51, 093001.
(15) Yang, T.-Y.; Gregori, G.; Pellet, N.; Grätzel, M.; Maier, J. The Significance of Ion Conduction in a Hybrid Organic-Inorganic LeadIodide-Based Perovskite Photosensitizer. Angew. Chem., Int. Ed. 2015, 54, 7905-7910.

(16) Delugas, P.; Caddeo, C.; Filippetti, A.; Mattoni, A. Thermally Activated Point Defect Diffusion in Methylammonium Lead Trihalide: Anisotropic and Ultrahigh Mobility of Iodine. J. Phys. Chem. Lett. 2016, 7, 2356-2361.

(17) Zhu, X.; Lee, J.; Lu, W. D. Iodine Vacancy Redistribution in Organic-Inorganic Halide Perovskite Films and Resistive Switching Effects. Adv. Mater. 2017, 29, 1700527.

(18) Li, C.; Tscheuschner, S.; Paulus, F.; Hopkinson, P. E.; Kießling, J.; Köhler, A.; Vaynzof, Y.; Huettner, S. Iodine Migration and Its Effect on Hysteresis in Perovskite Solar Cells. Adv. Mater. 2016, 28, 24462454.

(19) Kim, G. Y.; Senocrate, A.; Yang, T.-Y.; Gregori, G.; Grätzel, M.; Maier, J. Large Tunable Photoeffect on Ion Conduction in Halide Perovskites and Implications for Photodecomposition. Nat. Mater. 2018, 17, 445-449.

(20) Senocrate, A.; Moudrakovski, I.; Kim, G. Y.; Yang, T.-Y.; Gregori, G.; Grätzel, M.; Maier, J. The Nature of Ion Conduction in Methylammonium Lead Iodide: A Multimethod Approach. Angew. Chem., Int. Ed. 2017, 56, 7755-7759.

(21) Yuan, Y.; Chae, J.; Shao, Y.; Wang, Q.; Xiao, Z.; Centrone, A.; Huang, J. Photovoltaic Switching Mechanism in Lateral Structure Hybrid Perovskite Solar Cells. Adv. Energy Mater. 2015, 5, 1500615.

(22) Futscher, M. H.; Lee, J. M.; Wang, T.; Fakharuddin, A.; SchmidtMende, L.; Ehrler, B. Quantification of Ion Migration in $\mathrm{CH}_{3} \mathrm{NH}_{3} \mathrm{PbI}_{3}$ Perovskite Solar Cells by Transient Capacitance Measurements. 2018, arXiv:1801.08519. arXiv e-Print.

(23) deQuilettes, D. W.; Zhang, W.; Burlakov, V. M.; Graham, D. J.; Leijtens, T.; Osherov, A.; Bulovic, V.; Snaith, H. J.; Ginger, D. S.; Stranks, S. D. Photo-Induced Halide Redistribution in OrganicInorganic Perovskite Films. Nat. Commun. 2016, 7, 11683.

(24) Zhao, C.; Chen, B.; Qiao, X.; Luan, L.; Lu, K.; Hu, B. Revealing Underlying Processes Involved in Light Soaking Effects and Hysteresis Phenomena in Perovskite Solar Cells. Adv. Energy Mater. 2015, 5, 1500279.

(25) Belisle, R. A.; Nguyen, W. H.; Bowring, A. R.; Calado, P.; Li, X.; Irvine, S. J. C.; McGehee, M. D.; Barnes, P. R. F.; O’Regan, B. C. Interpretation of Inverted Photocurrent Transients in Organic Lead Halide Perovskite Solar Cells: Proof of the Field Screening by Mobile Ions and Determination of the Space Charge Layer Widths. Energy Environ. Sci. 2017, 10, 192-204.

(26) Wang, Q. Fast Voltage Decay in Perovskite Solar Cells Caused by Depolarization of Perovskite Layer. J. Phys. Chem. C 2018, 122, 48224827.

(27) Pockett, A.; Eperon, G. E.; Peltola, T.; Snaith, H. J.; Walker, A.; Peter, L. M.; Cameron, P. J. Characterization of Planar Lead Halide Perovskite Solar Cells by Impedance Spectroscopy, Open-Circuit Photovoltage Decay, and Intensity-Modulated Photovoltage/Photocurrent Spectroscopy. J. Phys. Chem. C 2015, 119, 3456-3465.

(28) Zarazua, I.; Bisquert, J.; Garcia-Belmonte, G. Light-Induced Space-Charge Accumulation Zone as Photovoltaic Mechanism in Perovskite Solar Cells. J. Phys. Chem. Lett. 2016, 7, 525-528.

(29) Zarazua, I.; Han, G.; Boix, P. P.; Mhaisalkar, S.; FabregatSantiago, F.; Mora-Seró, I.; Bisquert, J.; Garcia-Belmonte, G. Surface Recombination and Collection Efficiency in Perovskite Solar Cells From Impedance Analysis. J. Phys. Chem. Lett. 2016, 7, 5105-5113.

(30) Christians, J. A.; Schulz, P.; Tinkham, J. S.; Schloemer, T. H.; Harvey, S. P.; Tremolet de Villers, B. J.; Sellinger, A.; Berry, J. J.; Luther, J. M. Tailored Interfaces of Unencapsulated Perovskite Solar Cells for $>1,000$ Hour Operational Stability. Nat. Energy 2018, 3, 68-74.

(31) Saliba, M.; Matsui, T.; Seo, J.-Y.; Domanski, K.; Correa-Baena, J.P.; Nazeeruddin, M. K.; Zakeeruddin, S. M.; Tress, W.; Abate, A.; Hagfeldt, A.; et al. Cesium-Containing Triple Cation Perovskite Solar Cells: Improved Stability, Reproducibility and High Efficiency. Energy Environ. Sci. 2016, 9, 1989-1997. 
(32) Draguta, S.; Christians, J. A.; Morozov, Y. V.; Mucunzi, A.; Manser, J. S.; Kamat, P. V.; Luther, J. M.; Kuno, M. A Quantitative and Spatially Resolved Analysis of the Performance-Bottleneck in High Efficiency, Planar Hybrid Perovskite Solar Cells. Energy Environ. Sci. 2018, 11, 960-969.

(33) Domanski, K.; Roose, B.; Matsui, T.; Saliba, M.; Turren-Cruz, S.H.; Correa-Baena, J.-P.; Carmona, C. R.; Richardson, G.; Foster, J. M.; De Angelis, F.; et al. Migration of Cations Induces Reversible Performance Losses Over Day/Night Cycling in Perovskite Solar Cells. Energy Environ. Sci. 2017, 10, 604-613.

(34) Leijtens, T.; Eperon, G. E.; Pathak, S.; Abate, A.; Lee, M. M.; Snaith, H. J. Overcoming Ultraviolet Light Instability of Sensitized $\mathrm{TiO}_{2}$ With Meso-Superstructured Organometal Tri-halide Perovskite Solar Cells. Nat. Commun. 2013, 4, 2885.

(35) Tirmzi, A. M.; Dwyer, R. P.; Hanrath, T.; Marohn, J. A. Coupled Slow and Fast Charge Dynamics in Cesium Lead Bromide Perovskite. ACS Energy Lett. 2017, 2, 488-496.

(36) Denk, W.; Pohl, D. W. Local Electrical Dissipation Imaged by Scanning Force Microscopy. Appl. Phys. Lett. 1991, 59, 2171-2173.

(37) Stipe, B. C.; Mamin, H. J.; Stowe, T. D.; Kenny, T. W.; Rugar, D. Noncontact Friction and Force Fluctuations Between Closely Spaced Bodies. Phys. Rev. Lett. 2001, 87, 096801.

(38) Cockins, L.; Miyahara, Y.; Bennett, S. D.; Clerk, A. A.; Studenikin, S.; Poole, P.; Sachrajda, A.; Grutter, P. Energy Levels of Few-Electron Quantum Dots Imaged and Characterized by Atomic Force Microscopy. Proc. Natl. Acad. Sci. U.S.A. 2010, 107, 9496-9501.

(39) Lekkala, S.; Hoepker, N.; Marohn, J. A.; Loring, R. F. Charge Carrier Dynamics and Interactions in Electric Force Microscopy. J. Chem. Phys. 2012, 137, 124701.

(40) Lekkala, S.; Marohn, J. A.; Loring, R. F. Electric Force Microscopy of Semiconductors: Theory of Cantilever Frequency Fluctuations and Noncontact Friction. J. Chem. Phys. 2013, 139, 184702 .

(41) Cox, P. A.; Flagg, L. Q.; Giridharagopal, R.; Ginger, D. S. Cantilever Ringdown Dissipation Imaging for the Study of Loss Processes in Polymer/Fullerene Solar Cells. J. Phys. Chem. C 2016, 120, 12369-12376.

(42) Cox, P. A.; Waldow, D. A.; Dupper, T. J.; Jesse, S.; Ginger, D. S. Mapping Nanoscale Variations in Photochemical Damage of Polymer/ Fullerene Solar Cells With Dissipation Imaging. ACS Nano 2013, 7, 10405-10413.

(43) Crider, P. S.; Israeloff, N. E. Imaging Nanoscale Spatio-Temporal Thermal Fluctuations. Nano Lett. 2006, 6, 887-889.

(44) Stowe, T. D.; Kenny, T. W.; Thomson, D. J.; Rugar, D. Silicon Dopant Imaging by Dissipation Force Microscopy. Appl. Phys. Lett. 1999, 75, 2785-2787.

(45) Luria, J. L.; Hoepker, N.; Bruce, R.; Jacobs, A. R.; Groves, C.; Marohn, J. A. Spectroscopic Imaging of Photopotentials and Photoinduced Potential Fluctuations in a Bulk Heterojunction Solar Cell Film. ACS Nano 2012, 6, 9392-9401.

(46) Yazdanian, S. M.; Marohn, J. A.; Loring, R. F. Dielectric Fluctuations in Force Microscopy: Noncontact Friction and Frequency Jitter. J. Chem. Phys. 2008, 128, 224706.

(47) Hoepker, N.; Lekkala, S.; Loring, R. F.; Marohn, J. A. Dielectric Fluctuations Over Polymer Films Detected Using an Atomic Force Microscope. J. Phys. Chem. B 2011, 115, 14493-14500.

(48) Kuehn, S.; Loring, R. F.; Marohn, J. A. Dielectric Fluctuations and the Origins of Noncontact Friction. Phys. Rev. Lett. 2006, 96, 156103.

(49) Kuehn, S.; Marohn, J. A.; Loring, R. F. Noncontact Dielectric Friction. J. Phys. Chem. B 2006, 110, 14525-14528.

(50) Labardi, M.; Lucchesi, M.; Prevosto, D.; Capaccioli, S. Broadband Local Dielectric Spectroscopy. Appl. Phys. Lett. 2016, 108, 182906.

(51) Bergmann, V. W.; Weber, S. A. L.; Javier Ramos, F.; Nazeeruddin, M. K.; Grätzel, M.; Li, D.; Domanski, A. L.; Lieberwirth, I.; Ahmad, S.; Berger, R. Real-Space Observation of Unbalanced Charge Distribution Inside a Perovskite-sensitized Solar Cell. Nat. Commun. 2014, 5, 5001.
(52) Li, J.-J.; Ma, J.-Y.; Ge, Q.-Q.; Hu, J.-S.; Wang, D.; Wan, L.-J. Microscopic Investigation of Grain Boundaries in Organolead Halide Perovskite Solar Cells. ACS Appl. Mater. Interfaces 2015, 7, 2851828523.

(53) Yun, J. S.; Seidel, J.; Kim, J.; Soufiani, A. M.; Huang, S.; Lau, J.; Jeon, N. J.; Seok, S. I.; Green, M. A.; Ho-Baillie, A. Critical Role of Grain Boundaries for Ion Migration in Formamidinium and Methylammonium Lead Halide Perovskite Solar Cells. Adv. Energy Mater. 2016, 6, 1600330.

(54) Yuan, Y.; Li, T.; Wang, Q.; Xing, J.; Gruverman, A.; Huang, J. Anomalous Photovoltaic Effect in Organic-inorganic Hybrid Perovskite Solar Cells. Sci. Adv. 2017, 3, No. e1602164.

(55) Garrett, J. L.; Tennyson, E. M.; Hu, M.; Huang, J.; Munday, J. N.; Leite, M. S. Real-Time Nanoscale Open-Circuit Voltage Dynamics of Perovskite Solar Cells. Nano Lett. 2017, 17, 2554-2560.

(56) Collins, L.; Ahmadi, M.; Wu, T.; Hu, B.; Kalinin, S. V.; Jesse, S. Breaking the Time Barrier in Kelvin Probe Force Microscopy: Fast Free Force Reconstruction Using the G-Mode Platform. ACS Nano 2017, $11,8717-8729$

(57) Salado, M.; Kokal, R. K.; Calio, L.; Kazim, S.; Deepa, M.; Ahmad, S. Identifying the Charge Generation Dynamics in $\mathrm{Cs}^{+}$-based Triple Cation Mixed Perovskite Solar Cells. Phys. Chem. Chem. Phys. 2017, 19, 22905-22914.

(58) Xiao, C.; Wang, C.; Ke, W.; Gorman, B. P.; Ye, J.; Jiang, C.-S.; Yan, Y.; Al-Jassim, M. M. Junction Quality of $\mathrm{SnO}_{2}$-Based Perovskite Solar Cells Investigated by Nanometer-Scale Electrical Potential Profiling. ACS Appl. Mater. Interfaces 2017, 9, 38373-38380.

(59) Will, J.; Hou, Y.; Scheiner, S.; Pinkert, U.; Hermes, I. M.; Weber, S. A. L.; Hirsch, A.; Halik, M.; Brabec, C.; Unruh, T. Evidence of Tailoring the Interfacial Chemical Composition in Normal Structure Hybrid Organohalide Perovskites by a Self-Assembled Monolayer. ACS Appl. Mater. Interfaces 2018, 10, 5511-5518.

(60) Birkhold, S. T.; Precht, J. T.; Liu, H.; Giridharagopal, R.; Eperon, G. E.; Schmidt-Mende, L.; Li, X.; Ginger, D. S. Interplay of Mobile Ions and Injected Carriers Creates Recombination Centers in Metal Halide Perovskites Under Bias. ACS Energy Lett. 2018, 3, 1279-1286.

(61) Birkhold, S. T.; Precht, J. T.; Giridharagopal, R.; Eperon, G. E.; Schmidt-Mende, L.; Ginger, D. S. Direct Observation and Quantitative Analysis of Mobile Frenkel Defects in Metal Halide Perovskites Using Scanning Kelvin Probe Microscopy. J. Phys. Chem. C 2018, 122, 12633-12639.

(62) Collins, L.; Ahmadi, M.; Qin, J.; Liu, Y.; Ovchinnikova, O. S.; Hu, B.; Jesse, S.; Kalinin, S. V. Time Resolved Surface Photovoltage Measurements Using a Big Data Capture Approach to KPFM. Nanotechnology 2018, 29, 445703.

(63) Coffey, D. C.; Ginger, D. S. Time-Resolved Electrostatic Force Microscopy of Polymer Solar Cells. Nat. Mater. 2006, 5, 735-740.

(64) Reid, O. G.; Rayermann, G. E.; Coffey, D. C.; Ginger, D. S. Imaging Local Trap Formation in Conjugated Polymer Solar Cells: A Comparison of Time-Resolved Electrostatic Force Microscopy and Scanning Kelvin Probe Imaging. J. Phys. Chem. C 2010, 114, 2067220677.

(65) Giridharagopal, R.; Rayermann, G. E.; Shao, G.; Moore, D. T.; Reid, O. G.; Tillack, A. F.; Masiello, D. J.; Ginger, D. S. Submicrosecond Time Resolution Atomic Force Microscopy for Probing Nanoscale Dynamics. Nano Lett. 2012, 12, 893-898.

(66) Karatay, D. U.; Harrison, J. S.; Glaz, M. S.; Giridharagopal, R.; Ginger, D. S. Fast Time-Resolved Electrostatic Force Microscopy: Achieving Sub-Cycle Time Resolution. Rev. Sci. Instrum. 2016, 87, 053702 .

(67) Dwyer, R. P.; Nathan, S. R.; Marohn, J. A. Microsecond Photocapacitance Transients Observed Using a Charged Microcantilever as a Gated Mechanical Integrator. Sci. Adv. 2017, 3, No. e1602951.

(68) Crider, P. S.; Majewski, M. R.; Zhang, J.; Oukris, H.; Israeloff, N. E. Local Dielectric Spectroscopy of Polymer Films. Appl. Phys. Lett. 2007, 91, 013102.

(69) Dwyer, R. P.; Harrell, L. E.; Marohn, J. A. Lagrangian and Impedance Spectroscopy Treatments of Electric Force Microscopy. 2018, arXiv:1807.01219. arXiv e-Print. 
(70) Wojciechowski, K.; Saliba, M.; Leijtens, T.; Abate, A.; Snaith, H. J. Sub- $150{ }^{\circ} \mathrm{C}$ Processed Meso-Superstructured Perovskite Solar Cells with Enhanced Efficiency. Energy Environ. Sci. 2014, 7, 1142-1147.

(71) Jiang, Q.; Zhang, L.; Wang, H.; Yang, X.; Meng, J.; Liu, H.; Yin, Z.; Wu, J.; Zhang, X.; You, J. Enhanced Electron Extraction Using $\mathrm{SnO}_{2}$ for High-efficiency Planar-structure $\mathrm{HC}\left(\mathrm{NH}_{2}\right)_{2} \mathrm{PbI}_{3}$-based Perovskite Solar Cells. Nat. Energy 2016, 2, 16177.

(72) Dunfield, S. P.; Moore, D. T.; Klein, T. R.; Fabian, D. M.; Christians, J. A.; Dixon, A. G.; Dou, B.; Ardo, S.; Beard, M. C.; Shaheen, S. E.; et al. Curtailing Perovskite Processing Limitations via Lamination at the Perovskite/Perovskite Interface. ACS Energy Lett. 2018, 3, 11921197.

(73) Luria, J. L. Spectroscopic Characterization of Charge Generation and Trapping in Third-Generation Solar Cell Materials Using Wavelength- and Time-Resolved Electric Force Microscopy. Ph.D. Thesis, Cornell University, Ithaca, NY, 2011.

(74) Kerner, R. A.; Rand, B. P. Ionic-Electronic Ambipolar Transport in Metal Halide Perovskites: Can Electronic Conductivity Limit Ionic Diffusion? J. Phys. Chem. Lett. 2017, 9, 132-137.

(75) Walsh, A.; Stranks, S. D. Taking Control of Ion Transport in Halide Perovskite Solar Cells. ACS Energy Lett. 2018, 3, 1983-1990.

(76) Ginting, R. T.; Jung, E.-S.; Jeon, M.-K.; Jin, W.-Y.; Song, M.; Kang, J.-W. Low-Temperature Operation of Perovskite Solar Cells: With Efficiency Improvement and Hysteresis-less. Nano Energy 2016, 27, 569-576.

(77) Zou, Y.; Holmes, R. J. Temperature-Dependent Bias Poling and Hysteresis in Planar Organo-Metal Halide Perovskite Photovoltaic Cells. Adv. Energy Mater. 2016, 6, 1501994.

(78) Wehrenfennig, C.; Eperon, G. E.; Johnston, M. B.; Snaith, H. J.; Herz, L. M. High Charge Carrier Mobilities and Lifetimes in Organolead Trihalide Perovskites. Adv. Mater. 2013, 26, 1584-1589.

(79) de Quilettes, D. W.; Vorpahl, S. M.; Stranks, S. D.; Nagaoka, H.; Eperon, G. E.; Ziffer, M. E.; Snaith, H. J.; Ginger, D. S. Impact of Microstructure on Local Carrier Lifetime in Perovskite Solar Cells. Science 2015, 348, 683-686.

(80) Hutter, E. M.; Eperon, G. E.; Stranks, S. D.; Savenije, T. J. Charge Carriers in Planar and Meso-Structured Organic-Inorganic Perovskites: Mobilities, Lifetimes, and Concentrations of Trap States. J. Phys. Chem. Lett. 2015, 6, 3082-3090.

(81) deQuilettes, D. W.; Koch, S.; Burke, S.; Paranji, R. K.; Shropshire, A. J.; Ziffer, M. E.; Ginger, D. S. Photoluminescence Lifetimes Exceeding $8 \mu \mathrm{s}$ and Quantum Yields Exceeding 30\% in Hybrid Perovskite Thin Films by Ligand Passivation. ACS Energy Lett. 2016, 2, 438-444.

(82) Chen, Y.; Yi, H. T.; Wu, X.; Haroldson, R.; Gartstein, Y. N.; Rodionov, Y. I.; Tikhonov, K. S.; Zakhidov, A.; Zhu, X.-Y.; Podzorov, V. Extended Carrier Lifetimes and Diffusion in Hybrid Perovskites Revealed by Hall Effect and Photoconductivity Measurements. Nat. Commun. 2016, 7, 12253.

(83) Olthof, S. Research Update: The Electronic Structure of Hybrid Perovskite Layers and Their Energetic Alignment in Devices. APL Mater. 2016, 4, 091502.

(84) Ou, Q.-D.; Li, C.; Wang, Q.-K.; Li, Y.-Q.; Tang, J.-X. Recent Advances in Energetics of Metal Halide Perovskite Interfaces. Adv. Mater. Interfaces 2017, 4, 1600694.

(85) Dou, B.; Miller, E. M.; Christians, J. A.; Sanehira, E. M.; Klein, T. R.; Barnes, F. S.; Shaheen, S. E.; Garner, S. M.; Ghosh, S.; Mallick, A.; et al. High-Performance Flexible Perovskite Solar Cells on Ultrathin Glass: Implications of the TCO. J. Phys. Chem. Lett. 2017, 8, 49604966.

(86) Barsoum, M. W. Fundamentals of Ceramics; Taylor and Francis, 2003; Chapter 7.

(87) Morozovska, A. N.; Eliseev, E. A.; Bravina, S. L.; Ciucci, F.; Svechnikov, G. S.; Chen, L.-Q.; Kalinin, S. V. Frequency Dependent Dynamical Electromechanical Response of Mixed Ionic-Electronic Conductors. J. Appl. Phys. 2012, 111, 014107.

(88) Jamnik, J.; Maier, J. Treatment of the Impedance of Mixed Conductors Equivalent Circuit Model and Explicit Approximate Solutions. J. Electrochem. Soc. 1999, 146, 4183.
(89) Macdonald, J. R. Theory of space-charge polarization and electrode-discharge effects. J. Chem. Phys. 1973, 58, 4982-5001.

(90) Lai, W.; Haile, S. M. Impedance Spectroscopy as a Tool for Chemical and Electrochemical Analysis of Mixed Conductors: A Case Study of Ceria. J. Am. Ceram. Soc. 2005, 88, 2979-2997.

(91) Ciucci, F.; Hao, Y.; Goodwin, D. G. Impedance Spectra of Mixed Conductors: A 2D Study of Ceria. Phys. Chem. Chem. Phys. 2009, 11, 11243.

(92) Bertoluzzi, L.; Boix, P. P.; Mora-Sero, I.; Bisquert, J. Theory of Impedance Spectroscopy of Ambipolar Solar Cells With TrapMediated Recombination. J. Phys. Chem. C 2014, 118, 16574-16580.

(93) Bisquert, J.; Bertoluzzi, L.; Mora-Sero, I.; Garcia-Belmonte, G. Theory of Impedance and Capacitance Spectroscopy of Solar Cells With Dielectric Relaxation, Drift-Diffusion Transport, and Recombination. J. Phys. Chem. C 2014, 118, 18983-18991.

(94) Shi, D.; Adinolfi, V.; Comin, R.; Yuan, M.; Alarousu, E.; Buin, A.; Chen, Y.; Hoogland, S.; Rothenberger, A.; Katsiev, K.; et al. Low Trapstate Density and Long Carrier Diffusion in Organolead Trihalide Perovskite Single Crystals. Science 2015, 347, 519-522.

(95) Bi, C.; Shao, Y.; Yuan, Y.; Xiao, Z.; Wang, C.; Gao, Y.; Huang, J. Understanding the Formation and Evolution of Interdiffusion Grown Organolead Halide Perovskite Thin Films by Thermal Annealing. J. Mater. Chem. A 2014, 2, 18508-18514.

(96) Frost, J. M.; Butler, K. T.; Brivio, F.; Hendon, C. H.; van Schilfgaarde, M.; Walsh, A. Atomistic Origins of High-Performance in Hybrid Halide Perovskite Solar Cells. Nano Lett. 2014, 14, 2584-2590.

(97) Richardson, G.; O’Kane, S. E. J.; Niemann, R. G.; Peltola, T. A.; Foster, J. M.; Cameron, P. J.; Walker, A. B. Can Slow-moving Ions Explain Hysteresis in the Current-voltage Curves of Perovskite Solar Cells? Energy Environ. Sci. 2016, 9, 1476-1485.

(98) Gomila, G.; Toset, J.; Fumagalli, L. Nanoscale Capacitance Microscopy of Thin Dielectric Films. J. Appl. Phys. 2008, 104, 024315.

(99) Zhao, J.; Deng, Y.; Wei, H.; Zheng, X.; Yu, Z.; Shao, Y.; Shield, J. E.; Huang, J. Strained Hybrid Perovskite Thin Films and Their Impact on the Intrinsic Stability of Perovskite Solar Cells. Sci. Adv. 2017, 3, No. eaao5616.

(100) Tsai, H.; Asadpour, R.; Blancon, J.-C.; Stoumpos, C. C.; Durand, O.; Strzalka, J. W.; Chen, B.; Verduzco, R.; Ajayan, P. M.; Tretiak, S.; et al. Light-Induced Lattice Expansion Leads to HighEfficiency Perovskite Solar Cells. Science 2018, 360, 67-70.

(101) Maier, J. On the Heterogeneous Doping of Ionic Conductors. Solid State Ionics 1986, 18-19, 1141-1145.

(102) Hoke, E. T.; Slotcavage, D. J.; Dohner, E. R.; Bowring, A. R.; Karunadasa, H. I.; McGehee, M. D. Reversible Photo-induced Trap Formation in Mixed-halide Hybrid Perovskites for Photovoltaics. Chem. Sci. 2015, 6, 613-617.

(103) Draguta, S.; Sharia, O.; Yoon, S. J.; Brennan, M. C.; Morozov, Y. V.; Manser, J. S.; Kamat, P. V.; Schneider, W. F.; Kuno, M. Rationalizing the Light-induced Phase Separation of Mixed Halide OrganicInorganic Perovskites. Nat. Commun. 2017, 8, 200.

(104) Mizusaki, J.; Arai, K.; Fueki, K. Ionic Conduction of the Perovskite-type Halides. Solid State Ionics 1983, 11, 203-211.

(105) Minns, J. L.; Zajdel, P.; Chernyshov, D.; van Beek, W.; Green, M. A. Structure and Interstitial Iodide Migration in Hybrid Perovskite Methylammonium Lead Iodide. Nat. Commun. 2017, 8, 15152.

(106) Li, W.; Liu, J.; Bai, F.-Q.; Zhang, H.-X.; Prezhdo, O. V. Hole Trapping by Iodine Interstitial Defects Decreases Free Carrier Losses in Perovskite Solar Cells: A Time-Domain Ab Initio Study. ACS Energy Lett. 2017, 2, 1270-1278. 